茴

SSCL-Preprint-556

February 1994

Distribution Category: 400
A. Drozhdin
N. Mokhov
B. Parker

Accidental Beam Loss in Superconducting Accelerators: Simulations, Consequences of Accidents and Protective Measures

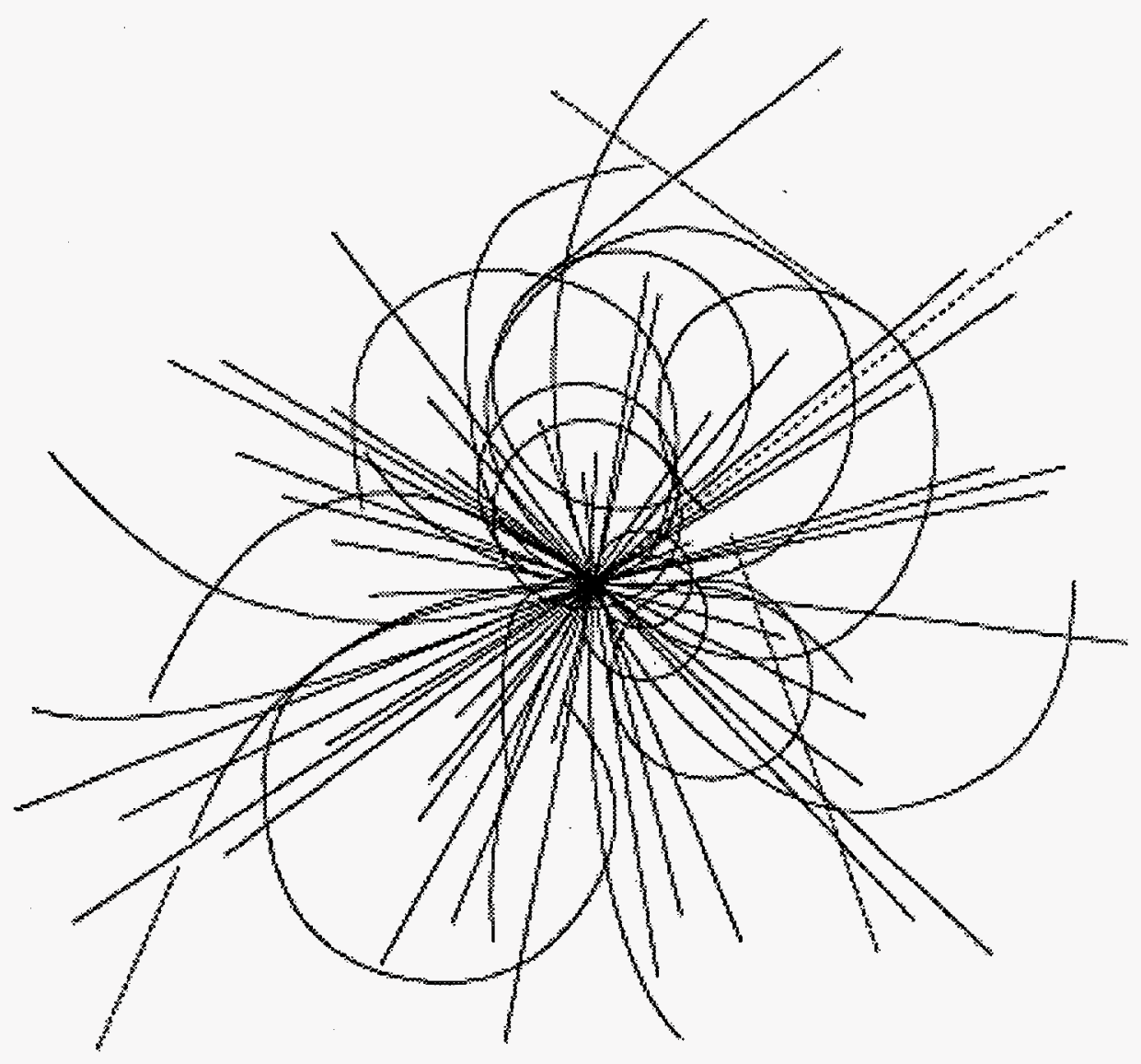

\section{Superconducting Super Collider Laboratory}

APPROVED FOR RELEASE OR PUBLICATION - O.R. PATENT GROUP BY. CO.........DATE. $6.7 / \% 5$. 


\section{Disclaimer Notice}

This report was prepared as an account of work sponsored by an agency of the United States Govemment. Neither the United States Government or any agency thereot, nor any of their employees, makes any warranty, express or implied, or assumes any legal liability or responsibility for the accuracy, completeness, or usefulness of any information, apparatus, product, or process disclosed, or represents that its use would not infringe privately owned rights. Reference herein to any specific commercial product, process, or service by trade name, trademark, manufacturer, or otherwise, does not necessarily constitute or imply its endorsement, recommendation, or favoring by the United States Government or any agency thereof. The views and opinions of authors expressed herein do not necessarily state or reflect those of the United States Government or any agency thereof.

Superconducting Super Collider Laboratory is an equal opportunity employer. 


\section{DISCLAIMER}

Portions of this document may be illegible in electronic image products. Images are produced from the best available original document. 
SSCL-Preprint-556

\title{
Accidental Beam Loss in Superconducting Accelerators: Simulations, Consequences of Accidents and Protective Measures*
}

\author{
A. Drozhdin, N. Mokhov, and B. Parker \\ Superconducting Super Collider Laboratory ${ }^{\dagger}$ \\ 2550 Beckleymeade Ave. \\ Dallas, TX 75237, USA
}

February 1994

${ }^{*}$ To be submitted to the Journal of Nuclear Instruments and Methods in Physics Research.

†Operated by the Universities Research Association, Inc., for the U.S. Department of Energy under Contract No. DE-AC35-89ER40486. 


\title{
Accidental Beam Loss in Superconducting Accelerators: Simulations, Consequences of Accidents and Protective Measures
}

\author{
A. Drozhdin, N. Mokhov, and B. Parker
}

\begin{abstract}
The consequences of an accidental beam loss in superconducting accelerators and colliders of the next generation range from the mundane to rather dramatic, $i . e$, from superconducting magnet quench, to overheating of critical components, to a total destruction of some units via explosion. Specific measures are required to minimize and eliminate such events as much as practical. In this paper we study such accidents taking the Superconducting Supercollider complex as an example. Particle tracking, beam loss and energy deposition calculations were done using the realistic machine simulation with the Monte-Carlo codes MARS12 and STRUCT. Protective measures for minimizing the damaging effects of prefire and misfire of injection and extraction kicker magnets are proposed here.
\end{abstract}




\section{Introduction}

The circulating beam energy at future high intensity accelerators is high enough to cause severe damage to the equipment. The Superconducting Super Collider (SSC) beam would have contained approximately $420 \mathrm{MJ}$ of circulating beam energy per ring at the operating design point of $20 \mathrm{TeV} / \mathrm{c}$ and $70 \mathrm{~mA}$ [1]. This energy is equivalent to that stored in about $100 \mathrm{~kg}$ of high explosives. The Collider abort system uses fast extraction to divert the beam to a massive graphite absorber for normal termination of the operating cycle or in any of a number of predefined fault modes. The abort kicker magnet system consists of 24 pulsed magnets having a rise time of about $3 \mu \mathrm{s}$. Normally this system is triggered during the $4 \mu \mathrm{s}$ "abort gap" in the circulating beam. If any kicker prefires or misfires, some fraction of the beam may not reach the absorber. Accidental beam loss consequences in the Collider range from superconducting magnet quenches, to overheating of some components, to total destruction of some units through their explosion $[2,3]$. The situation is similar in the High Energy Booster (HEB), the $2 \mathrm{TeV}$ superconducting injector to the Collider, and for other machines under design (LHC, TESLA etc.). Specific measures are required to mitigate and possibly to eliminate such events $[4,5]$. In this paper we further study such accidents. Material heating and radiation generation are studied using full scale machine simulations with STRUCT code [6] and Monte-Carlo energy deposition calculations with MARS12 [7]. Protective measures for minimizing the damaging effects of prefires and misfires are then proposed. These Supercollider and HEB results are applicable to other accelerators of such scale.

\section{Beam collimation system and shadow protectors}

To provide reliable operation of a superconducting accelerator and collider experiments a multi-component beam collimation system must be incorporated in the machine [8-10]. For the Collider, collimator locations in the West Utility and Interaction Regions (IRs) are presented in figs. 1 and 2 and table 1 [9]. These collimators are positioned at $20 \sigma$ with 
respect to the Collider closed orbit. The admittance of the machine is $729 \mathrm{~mm} . \mathrm{mrad}$ or $27 \sigma$ of the circulating beam at the top energy, i.e., collimators are placed only $7 \sigma$ inside the physical aperture of the Collider. During a beam misbehavior, even a small portion of the beam is enough to destroy any small aperture component. These are, first of all, septa of the Lambertson magnets, scrapers and collimators. The longitudinal distribution of peak temperature in a septum is shown in fig. 3 for an unsynchronized abort of a $20-\mathrm{TeV}$ beam. One sees that the first meter of the steel septum would be instantaneously melted.

To protect components, one can utilize a specific feature of beam-induced shower development in the $\mathrm{TeV}$ region, i.e., that the energy deposition density at cascade maximum is determined by electromagnetic showers, induced by $\pi^{0}$-decays [11]. Consequently, the peak energy deposition in light materials is lower than in heavy ones proportionally to a power of the Z-ratio. We find that the best solution is to put a graphite shadow right in front of a critical component. The shadow piece is an inert device with an aperture the same as that of the adjacent component which it is protecting. In fig. 3 we show that the expected temperature profile in graphite is quite different from that found in steel, with a peak temperature of about $800^{\circ} \mathrm{C}$. The length of a shadow shield is chosen to contain most of a cascade that is 5 meters at $20 \mathrm{TeV}$. Another criterion to the shadow length is that an instantaneous peak temperature in the downstream component must be below some limit, which we take to be $500{ }^{\circ} \mathrm{C}$ for steel. The longitudinal distribution of temperature in the CGWUT2 shadow/collimator pair immediately after an unsynchronized beam abort is shown in fig. 4. Peak temperature in the steel section is reduced to $380{ }^{\circ} \mathrm{C}$, whereas it is almost $900^{\circ} \mathrm{C}$ in the 4-m long graphite shadow.

At lower energies, the situation becomes much more favorable; a $2 \mathrm{TeV}$ unsynchronized abort in the Collider results in a maximum temperature rise in the steel septum of $450{ }^{\circ} \mathrm{C}$ "only." In the HEB it is $550{ }^{\circ} \mathrm{C}$ in the collider mode, but is still well 
above a steel melting point for the test beam intensity $10^{14} \mathrm{ppp}$, so again a graphite shadow of about 3-m length is required.

\section{Abort kicker prefire and unsynchronized abort}

The abort kicker prefire results in high amplitude coherent betatron oscillations of the beam. The disturbed beam can then induce collimator jaws overheating up to hundreds of degrees centigrade. Again the worst situation in the Collider takes place at $20 \mathrm{TeV}$. Simulation of this process has been done with the following assumptions: circulating beam has been cleaned up to the $10 \sigma$ level by the scraper, $99 \%$ of the circulating beam is inside the $4 \sigma$ region, and $1 \%$ of the beam is between 4 and $10 \sigma$. In the worst case, when prefire of an abort kicker takes place just after the longitudinal abort gap, one needs to wait one turn to abort the beam. The overheating of the IR collimator CLESIRT exceeds considerably the steel melting point. To avoid overheating of this collimator one should decrease the interval of time between a prefire and the start of the next 23 kickers to less than $5 \mu$ s. Unfortunately, the kicker pulse rise time is unlikely to be contained within the gap in the longitudinal distribution of the circulating beam (unsynchronized abort). Results of a simulation of beam loss during the $3 \mu$ s kicker rise time are presented in fig. 5 . At kicker low field level, halo particles are intercepted by the collimator CLESIRT in the IR. The calculated temperature profile is shown in fig. 6 for the innermost collimator surface and $1.5 \mathrm{~mm}$ deep in the collimator body. The maximum temperature rise in this collimator is $400{ }^{\circ} \mathrm{C}$. At a level of about $10 \%$ of kicker strength the deflected beam is intercepted by a graphite shadow in front of the second collimator in the West Utility (see figs. 1 and 4). At about $40 \%$ level of kicker strength, the beam is intercepted by the graphite shadow of the Lambertson magnet (fig. 3).

There are two ways proposed to decrease the overheating of collimators and shadows:

- Decrease the abort kicker rise time from $3 \mu$ s to $1 \mu$ s yielding a 3 -fold decrease in heating; 
- Compensate a prefired kicker via a module with the opposite magnetic field (antikicker). In this case the beam abort can be safely delayed until the abort gap, thus eliminating beam loss during the kicker rise time.

Recent simulations performed at SSCL suggest that the dynamic aperture of the Collider at the top energy is equal to about $12 \sigma$ and the lifetime of the particles with large betatron amplitudes, from 12 to $20 \sigma$, varies from 50 to 2 turns, respectively [12]. The lifetime is lower than one turn at amplitudes greater than $20 \sigma$. For this case, collimator jaws should be installed between $16-20 \sigma$ from the circulating beam axis to protect superconducting magnets against irradiation. Such a collimator would intercept a denser part of the circulating beam. This closer position causes a 10-fold increase in overheating as compared to the $20 \sigma$ position and the overheating of the collimator CLESIRT jaw during an unsynchronized abort is thus increased to an inadmissible temperature of $900^{\circ} \mathrm{C}$. The kicker risetime reduction method, outlined above, is ineffective in this case, and only an antikicker method is viable. For the second method, the collimator jaw overheating is strongly dependent upon the delay between prefire and start of the antikicker. The resulting kick and beam loss as a function of time for different delays $(1.2 \mu \mathrm{s}$ and $1.65 \mu \mathrm{s})$ are presented in figs. 7 and 8 . With a $1.8 \mu$ s delay, the resulting kick exceeds $75 \%$ of that for a single kicker and the collimator CLESIRT overheating exceeds the steel melting point. Collimator jaws overheating as a function of antikicker delay is shown in fig. 9. An acceptable temperature rise of about $300^{\circ} \mathrm{C}$ is exceeded for a $1.5 \mu$ delay between a prefire of the abort kicker and a start of the antikicker. We therefore conclude that ensuring a short $(<1.5 \mu \mathrm{s})$ delay is an important antikicker design requirement. Our simulations show that for large $(>20 \sigma)$ collimator settings, an unsynchronized abort is allowable if graphite shadows are used upstream of the abort Lambertson magnet and second collimator in the West Utility. For smaller collimator settings (between 16 and $20 \sigma$ ) an antikicker with less than $1.5 \mu$ s delay is needed to reduce Collider equipment overheating to tolerable levels. 


\section{HEB extraction kicker misfire}

The smallest apertures in the HEB-Collider transfer lines are situated at the upstream end of the first HEB Lambertson magnet and at the downstream end of the Collider injection Lambertson magnet (figs. 10, and 11). Extracted beam axis comes to within $5 \mathrm{~mm}$ of the HEB and Collider Lambertson magnet aperture limits, and $3.7 \mathrm{~mm}$ from the superconducting quadrupoles Q1 and QU3B apertures. The circulating beam passes through the "field free" hole of the Lambertson magnets $6 \mathrm{~mm}$ from the aperture edge. Note that the horizontal beam size, at $3 \sigma$ level, is equal to $1.5 \mathrm{~mm}$ and $1.7 \mathrm{~mm}$ in these magnets.

Misfire of a HEB extraction kicker sends in the extracted beam displacement closer to the septum of both the HEB and Collider Lambertson magnets. Results from our numerical simulations of the HEB kicker misfire are shown in figs. 12 and 13 for two extracted beam positions at the HEB and Collider level. The beam axis is $5 \mathrm{~mm}$ away from the Lambertson magnet aperture and $3 \mathrm{~mm}$ from the superconducting quadrupoles Q1 and QU3B apertures as shown in fig. 12. The beam is moved $0.7 \mathrm{~mm}$ closer to the Collider Lambertson magnet aperture in fig. 13. Beam loss is shown as a function of the beam+halo dimension. The extracted beam consists of $4 \sigma$ beam core and halo with $1 \%$ of the beam intensity outside the $4 \sigma$ size. Beam loss in QU3B and Q1 quadrupoles is shown in the same pictures during normal operation without any kicker misfire.

Displacement of the beam closer to the septum leaves the beam loss in the Lambertson magnets and collimator CLENIRT essentially unchanged, but eliminates particle loss in the superconducting quadrupoles Q1 and QU3B. The collimator CLENIRT and the HEB Lambertson magnet overheating remains below $100^{\circ} \mathrm{C}$ with the HEB scraper positioned at $d=14 \sigma$ distance from the beam axis. Beam loss during normal operation, as shown in fig. 12 , exceeds the fast quench level $\left(3 \times 10^{7}\right.$ protons per meter for the HEB and $3 \times 10^{6}$ protons $/ \mathrm{m}$ for the Collider quadrupoles) at $d=12 \sigma$. Therefore, one needs to ensure that the 
injected beam does not pass closer than $3.7 \mathrm{~mm}$ to the QU3B and Q1 apertures during injection.

\section{Collider injection kicker misfire and prefire}

A prefire of any one of the five injection kickers results in a coherent betatron oscillation of $1 / 8$ of a full Collider fill with a circulating beam amplitude of about $5 \mathrm{~mm}$ with respect to the closed orbit. Beam halo particles intercepted by the Collider elements induce overheating of superconducting magnets. Misfire of the injection kicker causes the same problem with the injected beam from the transfer line.

The rms closed orbit distortion at injection is equal to $1 \mathrm{~mm}$ in the Collider arc sections. Maximum $\beta$-function at injection is as high as $650 \mathrm{~m}$ in QL2A, QL2B, QL3A, QL3B of IRs and diameter of aperture is equal to $42 \mathrm{~mm}$. Displacement of the beam here, because of a beam separation, is equal to about $5 \mathrm{~mm}$. The beam pipe is as close as $16 \mathrm{~mm}$ to the circulating beam axis. There are eight such locations spread through the Collider lattice, so, it is difficult to keep the closed orbit of the beam within limit at every location. The Collider admittance determined following this consideration is equal to $290 \mathrm{~mm}$.mrad or $17 \sigma$ of circulating beam. Collimator jaws should be positioned at $16-17 \sigma$ from the beam axis to protect superconducting magnets against irradiation. Having collimators moved closer to the beam will increase the danger of collimator jaws overheating at abort and injection prefire or misfire.

In the case of an injection kicker misfire or prefire, the circulating beam must be aborted out of the Collider during the next few turns, because the transverse damping system cannot damp such a large injection beam displacement to an acceptable level. The following injection error scenario has been investigated. The HEB extracted beam passes through the beam transfer line to the Collider, where it remains six turns before being aborted through 
the beam abort line to the backstop. Collimator jaws are positioned at $16 \sigma$ with respect to the beam axis. Some additional assumptions are:

- $1 \%$ of the circulating beam is inside the region of 4 to $10 \sigma$ of the beam (halo definition);

- $\triangle B / B$ of the abort kicker is equal to $+12.5 \%$ (due to abort design for vertical painting);

- A full $1 / 8$ of the circulating beam protons are effected by the injection kicker.

Four cases of an injection kicker scheme with the above assumptions have been investigated: the kicker system segmented into $5,6,7$ or 8 modules. Total strength of the whole kicker system is kept fixed for all four cases. For the baseline 5 kicker scenario, beam loss in the first superconducting dogleg magnet in the West Utility results in a quench of that magnet with a peak instantaneous temperature rise of about $60{ }^{\circ} \mathrm{C}$ in case of $\mathrm{ID}=32.7 \mathrm{~mm}$ diameter of its beam pipe aperture. With ID $=42 \mathrm{~mm}$, calculated beam loss is below the fast quench limit.

The positions of the circulating and the aborted beam upstream of the Lambertson shadow are shown in fig. 14. A portion of the aborted beam is intercepted by the shadow, but the graphite shadow overheating remains below $3{ }^{\circ} \mathrm{C}$. The collimator overheating for prefire and misfire of the injection kicker versus jaw position is presented in fig. 15 for the 5 module case. The strong dependence of the maximum instantaneous temperature rise on the collimator jaw position suggests caution in the choice of the number of injection kicker modules. The collimator overheating for 6 modules versus jaw position is shown at fig. 16. The dependence on the kicker module number is presented in fig. 17. One concludes that in order to eliminate Collider equipment overheating at injection one needs to increase the number of injection kicker modules from the baseline 5 to at least 6 modules. 


\section{Injection kicker timing error}

Large injection kicker timing errors will result in serious problems for the unprotected superconducting equipment. For this reason, a few collimators in the HEB and Collider collimation systems are dedicated to such events $[9,10]$. But even at the lowest energy considered-200 GeV beam injected to the HEB-the overheating of some steel collimators can be unacceptably high $\left(>1000^{\circ} \mathrm{C}\right)$. So, a $1.5-\mathrm{m}$ long graphite shadow followed by $0.5-\mathrm{m}$ steel collimator should be incorporated into the HEB system instead of a purely metal unit.

Let's assume that the time mismatch of the kicker magnetic field pulse takes place during the commissioning period when unsynchronized injection is to be expected. Then in the Collider, the number of $2 \mathrm{TeV}$ protons in the injected beam is $1.6 \times 10^{13}$. For lower intensity during actual commissioning, one can simply rescale the results of the simulation accordingly. The HEB extraction kicker rise time duration is equal to $1.5 \mu \mathrm{s}$ (fig. 18). The HEB abort gap is only $0.2 \mu$ s longer. Kicker pulse time error causes loss of the beam both in the HEB Lambertson magnet septa and in the transfer line collimator.

At $33 \%$ of the full kicker strength the beam passes close to the septum inside the field free region of the Lambertson magnet, leading to the first peak in a beam loss distribution shown in fig. 19. The beam loss reaches the maximum at $42 \%$ of the kicker strength, at which point the whole beam is intercepted by the Lambertson's septa. Beyond 54\% of the kick the beam loss goes down, but beam loss in the transfer line collimator appears and goes up. The function of this collimator is to protect the Collider at two kicker modules misfire [5]. Beam loss reaches the maximum at $62 \%$ of kick and goes down to zero at $80 \%$ of the kicker strength. Beam loss in the Lambertson magnet is $1.4 \times 10^{11}$ protons and in the collimator $9 \times 10^{10}$ protons. This results in an instantaneous temperature rise the Lambertson magnet coils of $700{ }^{\circ} \mathrm{C}$ at peak. For HEB extraction kicker timing errors, beam 
loss in the Collider Lambertson magnet is three orders of magnitude lower and there is no meaningful loss in the downstream magnets.

Collider injection kicker timing errors cause the loss of circulating and injected beam particles (fig. 20). Circulating beam, deflected by the mismatched kicker, hits the inward side of the beam pipe. If the kicker is off, the newly injected beam heats the outward side of the beam pipe. At $25 \%$ of the kicker strength, beam loss arises in the IR collimators. These collimators are assumed placed at $16 \sigma$ position from the circulating beam axis at injection. A beam loss location depends on the kicker strength (fig. 21). At 55\% of the kick the beam loss location is moved closer to the kicker position. A few superconducting magnets are heated by the beam during the remaining rise up to $100 \%$; however, only a few magnets are heated simultaneously. At $100 \%$ of the kick the whole beam hits the second and third superconducting dipoles downstream QSD1 (fig. 22). These dipoles will be immediately melted. The overheating of the IR superconducting magnets and collimators during kicker rise time is about $300{ }^{\circ} \mathrm{C}$.

The injected beam, deflected by $100 \%$ of kick, is placed on the Collider closed orbit without any loss. Beam loss in the IR collimators will start at kicker fall to $75 \%$ of the kicker strength. With a kick less than $45 \%$, the beam loss location is moved closer to the kicker position. If the kicker is off, the injected beam heats the same two superconducting magnets, but on the opposite side of the beam pipe. These magnets are melted again. Overheating of the collimator CLENIRT is equal to $800^{\circ} \mathrm{C}$. To protect the above first two superconducting magnets against destruction at the catastrophic kicker time èrrors, we propose to put a two-jaw graphite collimator just upstream the quadrupole QSD1. This collimator consists of $2.8-\mathrm{m}$ long graphite jaws followed by $1-\mathrm{m}$ long steel jaws. 
Two important conclusions are:

1. The beam loss due to kicker timing errors causes Collider equipment melting at the HEB intensity of $1.6 \times 10^{13}$ protons/cycle. About $80 \%$ of the beam can hit just one superconducting magnet; therefore during commissioning, the maximum tolerable intensity is $8 \times 10^{10}$ protons per beam.

2. At the full HEB intensity of $1.6 \times 10^{13}$ protons/cycle, and with a kicker error less than $0.7 \mu \mathrm{s}$, the perturbed beam is intercepted by the collimators CLENIRT, CVENIRT, CHTIT, CLESIRT and CVESIRT in IR. The peak temperature rise in these collimators ranges from 300 to $800{ }^{\circ} \mathrm{C}$. With a time mismatch of more than $0.7 \mu \mathrm{s}$, a few superconducting magnets can be overheated to these same temperatures with dramatic consequences for the cryogenic system. Errors of less than $10 \%$ of the kicker strength (or $0.15 \mu$ s time error) do not effect significantly the beam loss in the Collider. Therefore, timing errors at the normal operating mode should be much less than $0.15 \mu \mathrm{s}$. This requirement only takes into account the radiation problem at injection, independently from any emittance growth considerations.

The beam loss in the Collider collimators and superconducting magnets at normal operation and unpredictable accidents, calculated in this work and in paper [9], are

summarized in table 2. A pedestal of $3 \times 10^{3}$ protons-per-meter-per-second due to beamgas interactions $[9,13]$ should be added to these values.

\section{Conclusions}

We have investigated the consequences of accidental beam loss in superconducting accelerators. Our Monte Carlo simulations of the SSC and HEB machine lattices, made with the MARS12 and STRUCT codes, verify that the consequences of accidental beam loss are indeed rather dramatic for unprotected machines. We found simple protective measures to mitigate such events. These measures typically include the introduction of 
shadow collimator/masking placed directly in front of critical components. For the injection kicker system we find it adequate to increase its degree segmentation from 5 to 6 independent modules. Finally, for the special case of prefire of an abort kicker module, an additional measure, the introduction of an antikicker module, is suggested. The results of this paper should be applicable to the future accelerators, e.g., the LHC and TESLA machines.

\section{Acknowledgements}

We wish to thank R. Meinke, R. Richardson, R. Schailey, R. Soundranayagam, and F. H. Wang for many useful discussions during the course of this work.

\section{References}

[1] "Site-Specific Conceptual Design of the Superconducting Super Collider," SSC Lab, July 1990.

[2] I. Baishev, A. Drozhdin, and N. Mokhov, "Beam Loss and Radiation Effects in the SSC Lattice Elements," SSCL-306 (1990).

[3] D. Wilson, C. Wingate, J. Goldstein, R. Godwin, and N. Mokhov, "Hydrodynamic Calculations of $20 \mathrm{TeV}$ Beam Interactions with the SSC Beam Dump," Proc. of IEEE Particle Accelerator Conference, p. 3090 (1993).

[4] A. Drozhdin, I. Baishev, N. Mokhov, B. Parker, R. Richardson, and J.Zhou, "Dealing with Abort Kicker Prefire in the Superconducting Super Collider," SSCL-329 (1993); Proc. of IEEE Particle Accelerator Conference, p. 3772 (1993).

[5] R. Soundranayagam, A. Drozhdin, N. Mokhov, B. Parker, R. Schailey, and F. Wang, "Consequences of Kicker Failure During HEB to Collider Injection and Possible Mitigation," SSCL-358 (1993); Proc. of IEEE Particle Accelerator Conference, p. 1360 (1993).

[6] I. Baishev, A. Drozhdin, and N. Mokhov, "STRUCT Code User's Rẹeference Manual," SSCL-MAN-0034 (1994).

[7] N. Mokhov, "MARS12 Code System," Proc. SARE Workshop, Santa Fe (1993); N.Mokhov, "MARS10 Code System User's Guide," Fermilab FN-509 (1989).

[8] M. Maslov, N. Mokhov, and I. Yazynin, "The SSC Beam Scraper System," SSCL-484 (1991).

[9] A. Drozhdin, N. Mokhov, J. Tompkins, and R. Soundranayagam, "Toward Design of the Collider Beam Collimation System," SSCL-Preprint-555 (1994). 
[10] A. Drozhdin, N. Mokhov, and R. Schailey, "HEB Beam Collimation System," SSCL-662 (1994).

[11] A. Kalinovsky, N. Mokhov, and Yu. Nikitin, "Passage of High Energy Particles Through Matter," AIP, N.Y. (1989).

[12] Y. Chai, Private Communication, Available at SSCL Library, April 1993.

[13] Collider Accelerator Utility Section, Element Specification (Level 3B), SSCL Document Control \# E10-000073, March 1993. 
Table 1.

Summary of types and numbers of scrapers and collimators.

\begin{tabular}{|c|c|c|c|}
\hline Name & Description & aw Length (m) & Shielding \\
\hline SCRHWUT & Horizontal Scraper - Top Ring & 1.2 & $0.65 \times 4.5 \mathrm{~m}$ \\
\hline SCRVWUT & Vertical Scraper - Top Ring & 1.2 & \\
\hline SCRHWUB & Horizontal Scraper - Bottom Ring & 1.2 & $0.65 \times 4.5 \mathrm{~m}$ \\
\hline SCRVWUB & Vertical Scraper - Top Ring & 1.2 & \\
\hline CHWUT1 & Horizontal - Top Ring, Warm Abort Dipole & 2.8 & $0.35 \times 4.5 \mathrm{~m}$ \\
\hline CHWUT2 & Horizontal - Top Lambertson Magnet & 2.8 & $0.35 \times 4.5 \mathrm{~m}$ \\
\hline CHTIT & Horizontal - Top Hinge & 2.8 & $0.35 \times 4.5 \mathrm{~m}$ \\
\hline CHWUB1 & Horizontal - Bottom Ring, Warm Abort Dipole & 2.8 & $0.35 \times 4.5 \mathrm{~m}$ \\
\hline CHWUB2 & Horizontal - Bottom Lambertson Magnet & 2.8 & $0.35 \times 4.5 \mathrm{~m}$ \\
\hline CHTIB & Horizontal - Bottom Hinge & 2.8 & $0.35 \times 4.5 \mathrm{~m}$ \\
\hline CVENIRT & Vertical - Top Ring, E-N IR, BV1M & 2.8 & $0.35 \times 4.5 \mathrm{~m}$ \\
\hline CVESIRT & Vertical - Top Ring, E-S IR, BV1P & 2.8 & $0.35 \times 4.5 \mathrm{~m}$ \\
\hline CVESIRB & Vertical - Bottom Ring, E-S IR, BV1M & 2.8 & $0.35 \times 4.5 \mathrm{~m}$ \\
\hline CVENIRB & Vertical - Bottom Ring, E-N IR, BV1P & 2.8 & $0.35 \times 4.5 \mathrm{~m}$ \\
\hline CLWUT1 & L-collimator - Top Ring, Dogleg Dipole & 2.8 & $0.35 \times 4.5 \mathrm{~m}$ \\
\hline CLWUB1 & L-collimator - Bottom Ring, Dogleg Dipole & 2.8 & $0.35 \times 4.5 \mathrm{~m}$ \\
\hline CLENIRT & L-collimator - Top Ring, E-N IR, BV1CM & 2.8 & $0.35 \times 4.5 \mathrm{~m}$ \\
\hline CLESIRT & L-collimator - Top Ring, E-S IR, BV1CP & 2.8 & $0.35 \times 4.5 \mathrm{~m}$ \\
\hline CLENIRB & L-collimator - Bottom Ring, E-N IR, BV1CP & 2.8 & $0.35 \times 4.5 \mathrm{~m}$ \\
\hline CLESIRB & L-collimator - Bottom Ring, E-S IR, BV1CM & 2.8 & $0.35 \times 4.5 \mathrm{~m}$ \\
\hline CGWUT1 & Graphite Collimator - Top Ring, QSD1 & 2.8 & No \\
\hline CGWUT2 & Graphite Collimator - Top Ring, Dogleg Dipole & 5.0 & $0.35 \times 5.5 \mathrm{~m}$ \\
\hline CGWUB1 & Graphite Collimator - Bottom Ring, QSD1 & 2.8 & No \\
\hline CGWUB2 & Graphite Collimator - Bottom Dogleg Dipole & 5.0 & $0.35 \times 5.5 \mathrm{~m}$ \\
\hline CFENIR1 & Fixed Aperture - East North IR & 3.0 & $0.75 \times 4.0 \mathrm{~m}$ \\
\hline CFENIR2 & Fixed Aperture - East North IR & 3.0 & $0.75 \times 4.0 \mathrm{~m}$ \\
\hline CFESIR1 & Fixed Aperture - East South IR & 3.0 & $0.75 \times 4.0 \mathrm{~m}$ \\
\hline CFESIR2 & Fixed Aperture - East South IR & 3.0 & $0.75 \times 4.0 \mathrm{~m}$ \\
\hline CFENIR1 & Neutral Beam Dump - East North IR & 2.0 & $0.65 \times 3.0 \mathrm{~m}$ \\
\hline CFENIR2 & Neutral Beam Dump - East North IR & 2.0 & $0.65 \times 3.0 \mathrm{~m}$ \\
\hline CFESIR1 & Neutral Beam Dump - East South IR & 2.0 & $0.65 \times 3.0 \mathrm{~m}$ \\
\hline CFESIR2 & Neutral Beam Dump - East South IR & 2.0 & $0.65 \times 3.0 \mathrm{~m}$ \\
\hline SSWUT & Shadow Septum - Top Ring Lambertson & 5.0 & $0.35 \times 5.5 \mathrm{~m}$ \\
\hline SSWUB & Shadow Septum - Bottom Ring Lambertson & 5.0 & $0.35 \times 5.5 \mathrm{~m}$ \\
\hline
\end{tabular}


Table 2.

Beam loss in the collider collimators and magnets.

$3 \times 10^{3} \mathrm{p} / \mathrm{m} / \mathrm{s}$ should be added to the rates given below.

\begin{tabular}{|l|l|l|l|l|l|}
\hline Component & $\begin{array}{l}\text { Scraping } \\
(\mathrm{p} / \mathrm{m} / \mathrm{s})\end{array}$ & $\begin{array}{l}\mathrm{pp}-\text {-collisions } \\
(\mathrm{p} / \mathrm{m} / \mathrm{s})\end{array}$ & $\begin{array}{l}\text { Unsynchro- } \\
\text { nized Abort } \\
(\mathrm{p})\end{array}$ & $\begin{array}{l}\text { Abort } \\
\text { Prefire }(\mathrm{p})\end{array}$ & $\begin{array}{l}\text { Injection } \\
\text { Prefire/Misfire } \\
(\mathrm{p})\end{array}$ \\
\hline SSWUT & $1.0 \times 10^{7}$ & & $1.5 \times 10^{11}$ & & \\
\hline LAMBERTSON & $1.0 \times 10^{4}$ & & & & \\
\hline CGWUT2 & $7.5 \times 10^{5}$ & & $3.0 \times 10^{11}$ & & \\
\hline CHWUT1 & $1.5 \times 10^{5}$ & & & & $6.0 \times 10^{9}$ \\
\hline CLWUT1 & $3.0 \times 10^{6}$ & & & & $7.0 \times 10^{9}$ \\
\hline CHWUT2 & $7.0 \times 10^{4}$ & $3.0 \times 10^{2}$ & & & \\
\hline CLENIRT & $1.5 \times 10^{4}$ & $7.3 \times 10^{2}$ & & & $1.0 \times 10^{10}$ \\
\hline CVENIRT & $6.0 \times 10^{2}$ & $7.0 \times 10^{5}$ & & & $8.0 \times 10^{8}$ \\
\hline CHTIT & $2.0 \times 10^{5}$ & $2.0 \times 10^{5}$ & & & $1.0 \times 10^{9}$ \\
\hline CLESIRT & $4.1 \times 10^{2}$ & $7.3 \times 10^{2}$ & $1.1 \times 10^{10}$ & $6.0 \times 10^{9}$ & \\
\hline CVESIRT & $6.0 \times 10^{3}$ & $7.0 \times 10^{5}$ & & & \\
\hline QL3A, B & $8.0 \times 10^{3}$ & $3.0 \times 10^{2}$ & & & \\
\hline QL2A, B & $2.0 \times 10^{2}$ & $2.0 \times 10^{2}$ & & & \\
\hline B, BS & $2.0 \times 10^{2}$ & $9.0 \times 10^{3}$ & & & \\
\hline
\end{tabular}




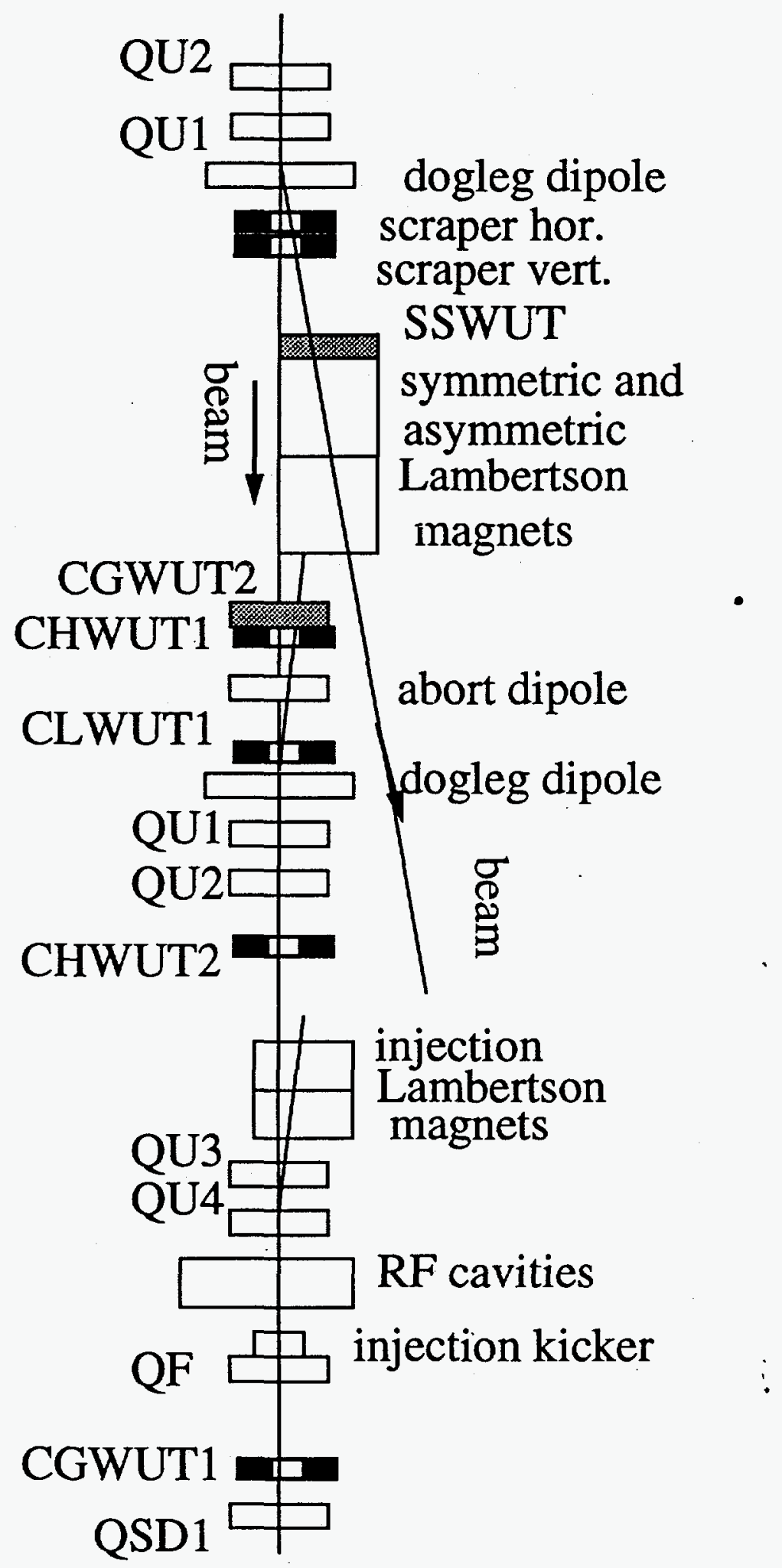

Fig. 1. Collimator locations in the Collider West Utility. 

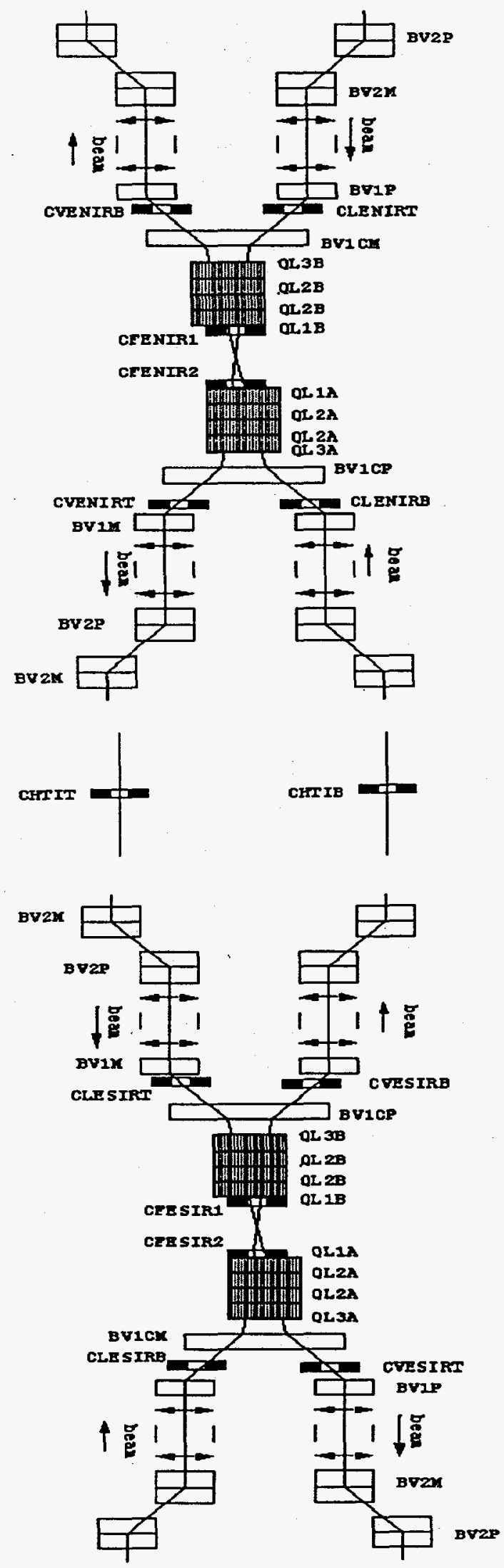

Fig. 2. Collimator locations in the Collider Interaction Regions. 


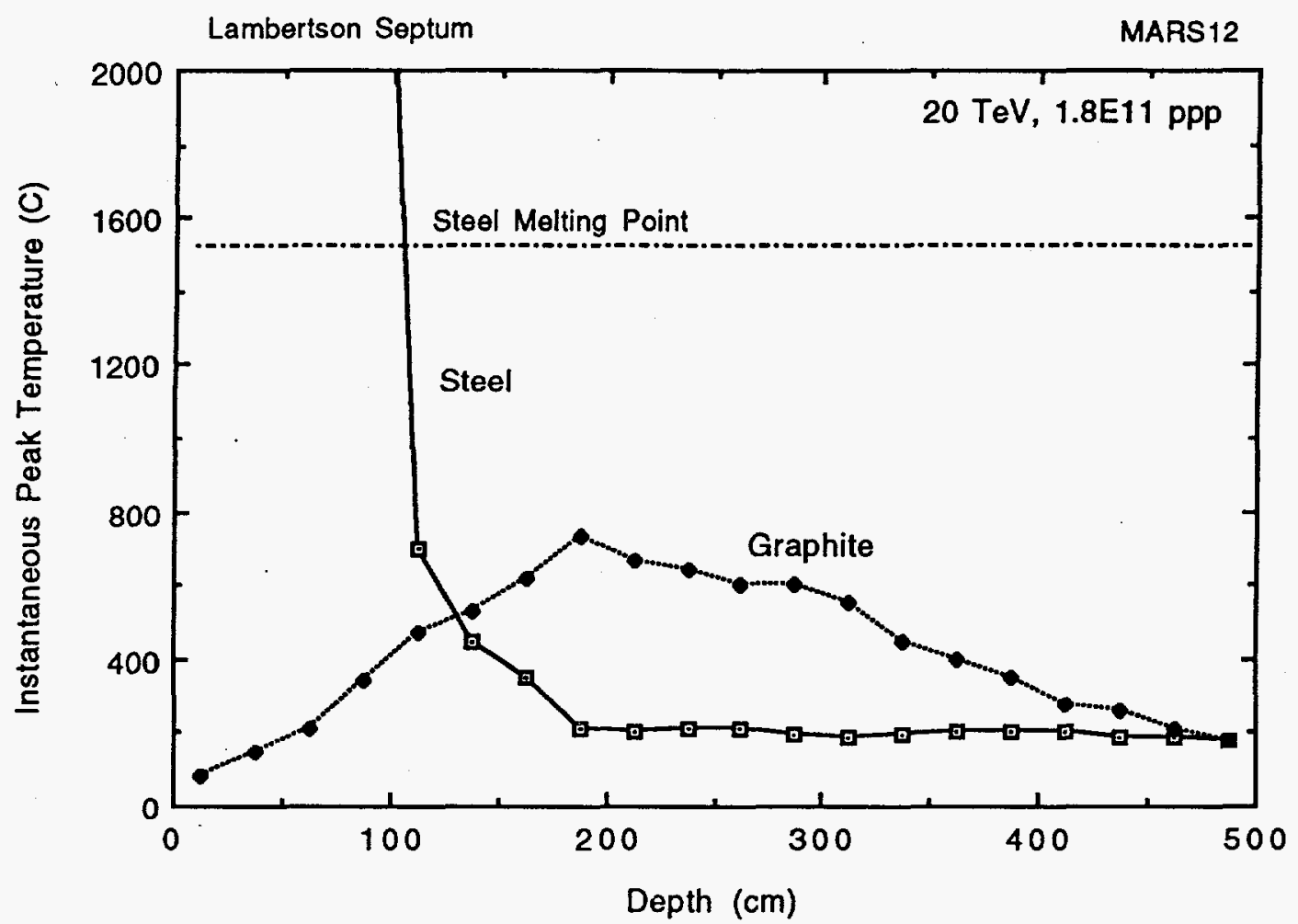

Fig. 3. Instantaneous maximum temperature in steel septum and graphite shadow vs depth at unsynchronized abort of $1.3 \times 10^{14}$ protons with $20 \mathrm{TeV}$ energy.

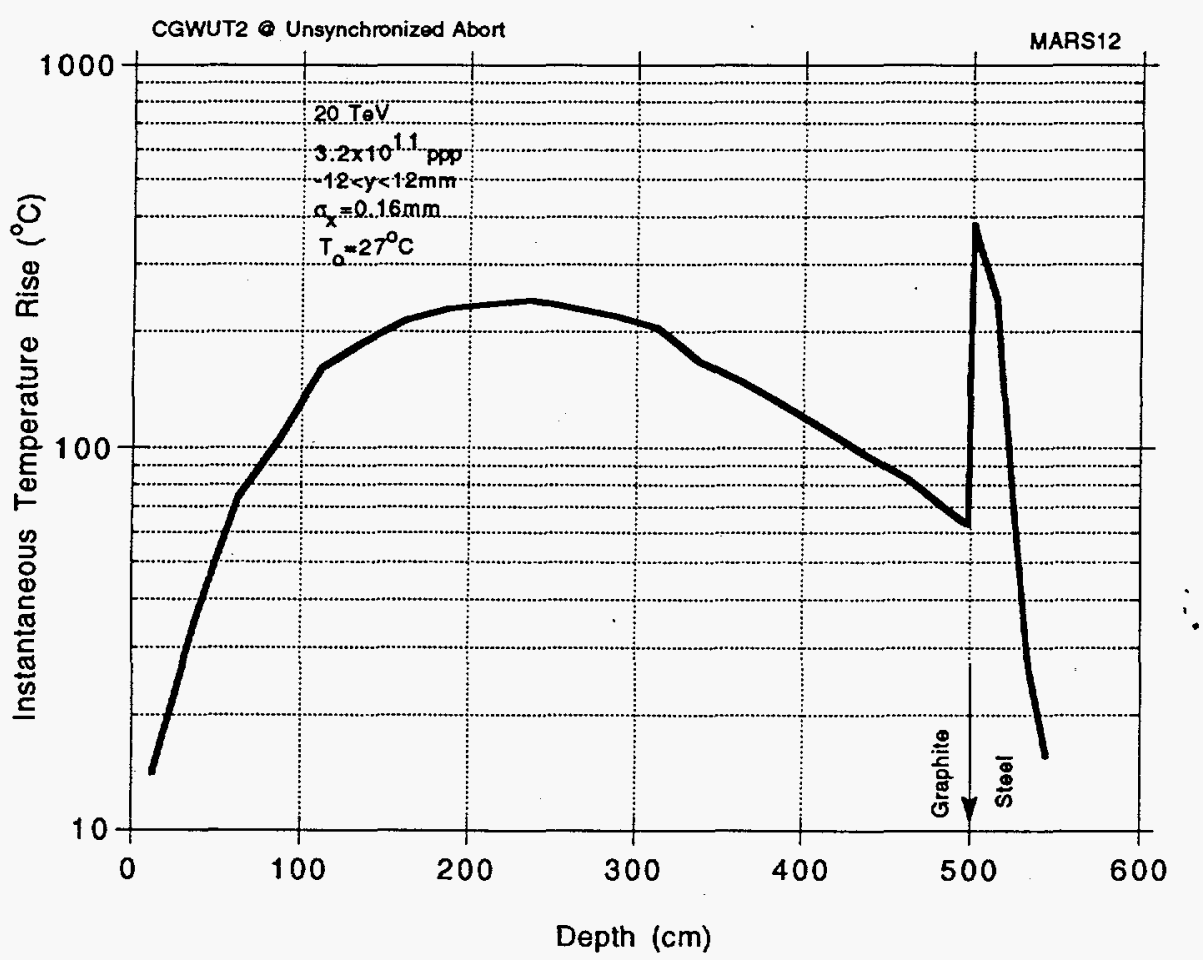

Fig. 4. Instantaneous maximum temperature in graphite shadow CGWUT2 followed by steel collimator at unsynchronized abort of $1.3 \times 10^{14}$ protons with $20 \mathrm{TeV}$ energy. 


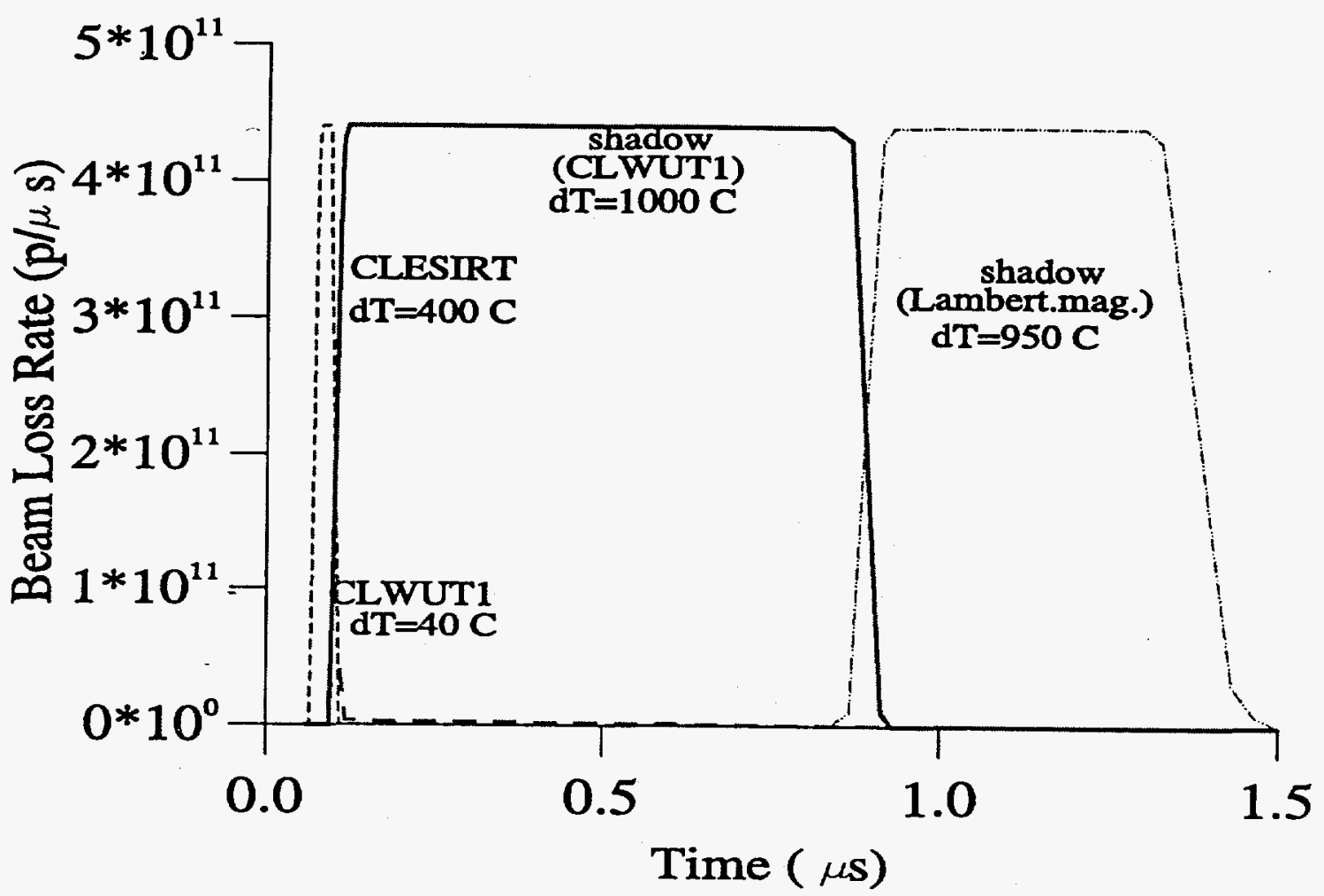

Fig. 5. Beam loss distribution during $3 \mu$ s collider kicker rise time at unsynchronized abort.

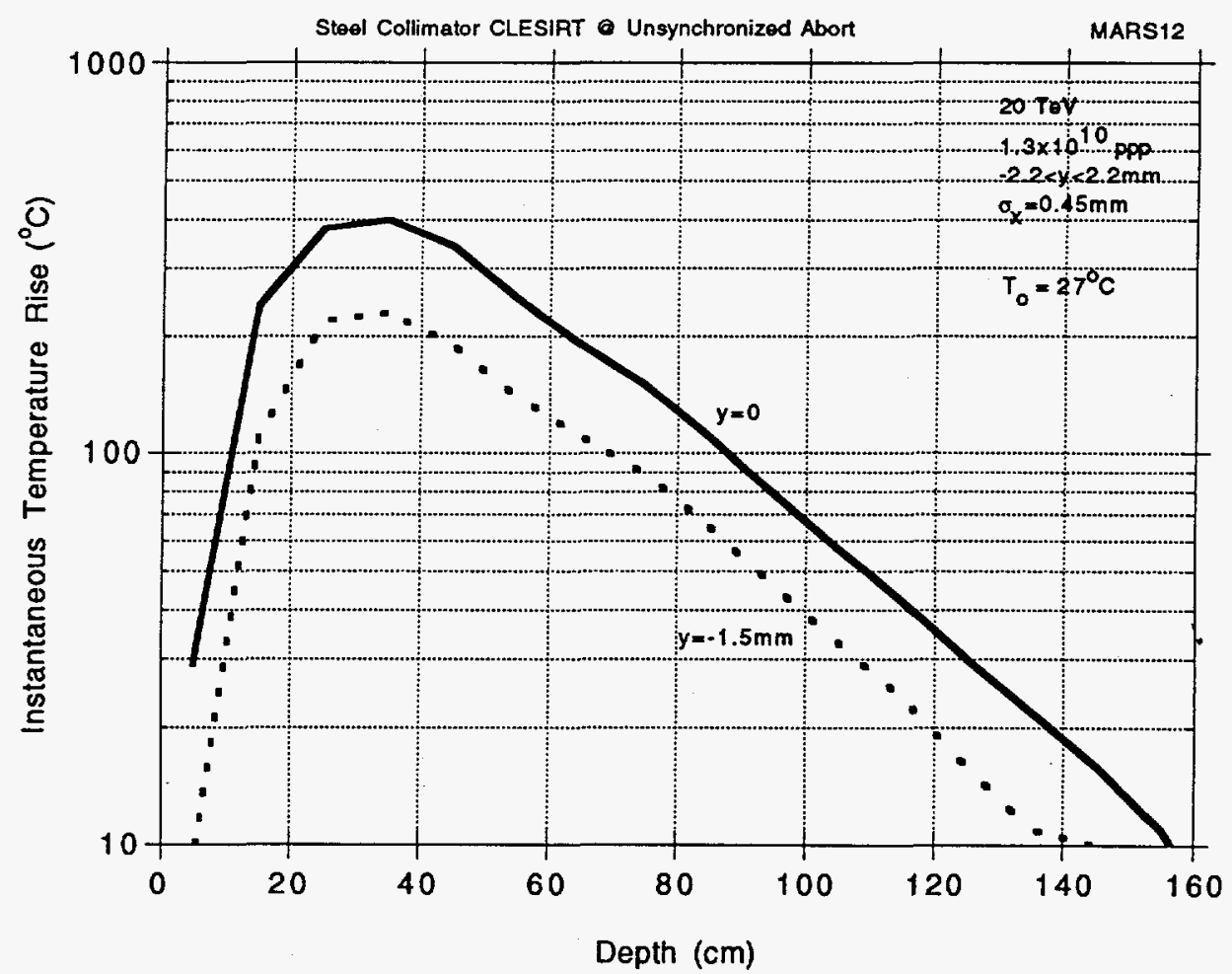

Fig. 6. Longitudinal temperature distribution in steel IR collimator CLESIRT at unsynchronized abort of $1.3 \times 10^{14}$ protons with $20 \mathrm{TeV}$ energy. 

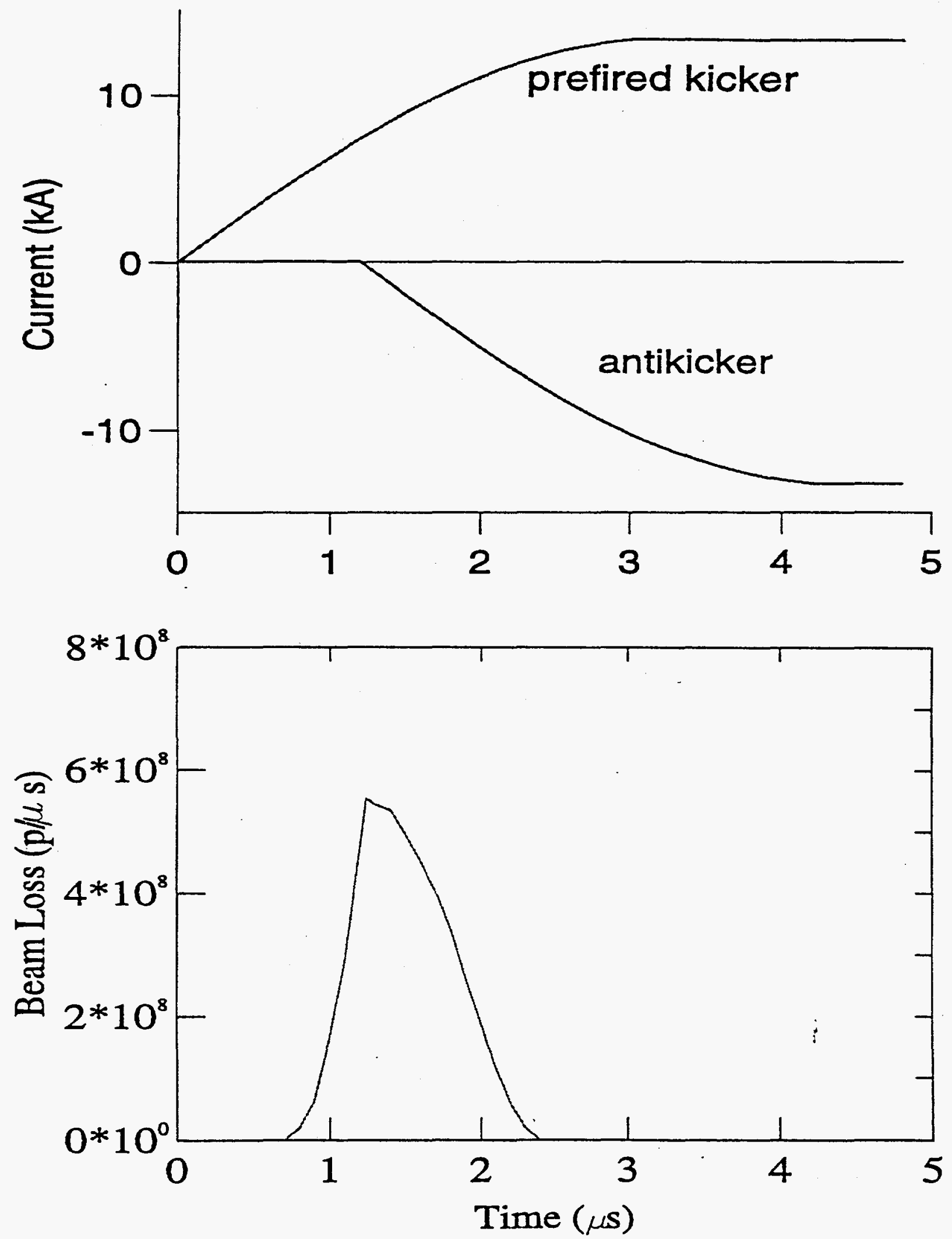

Fig. 7. Beam loss vs time for $1.2 \mu$ s antikicker delay. 

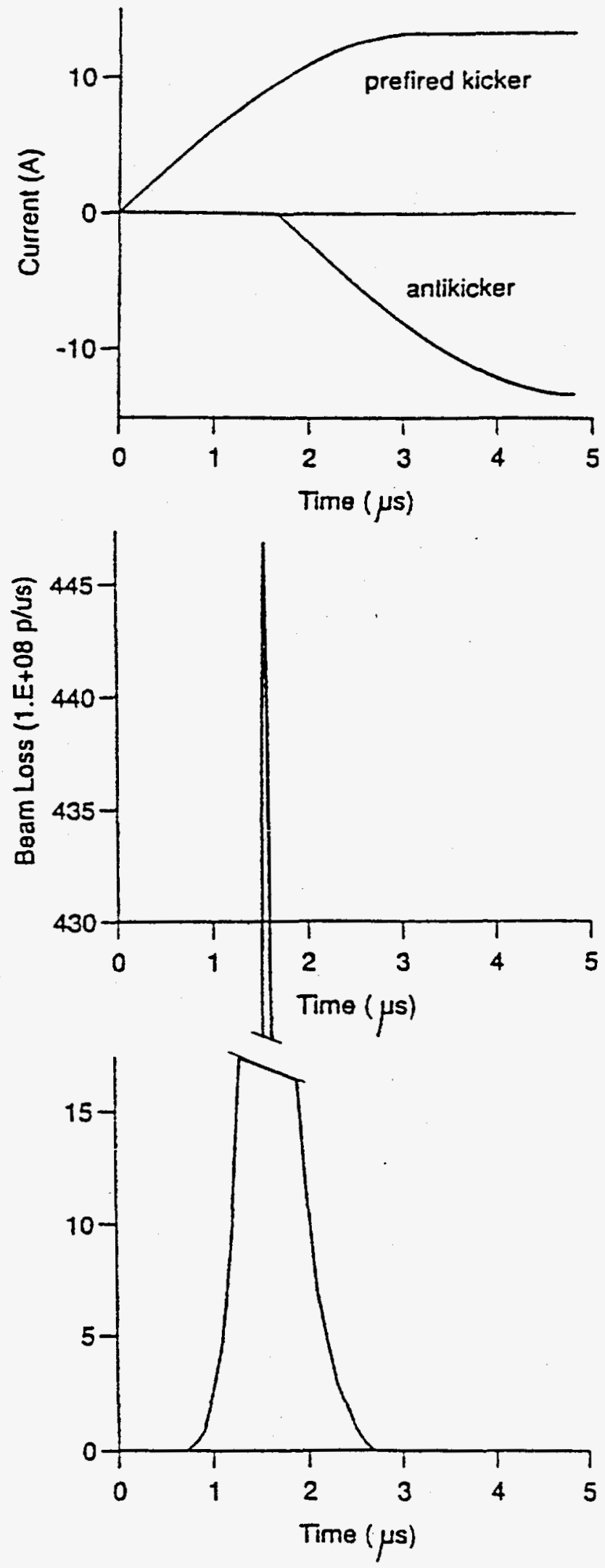

Fig. 8. Beam loss vs time for $1.65 \mu$ s antikicker delay. 


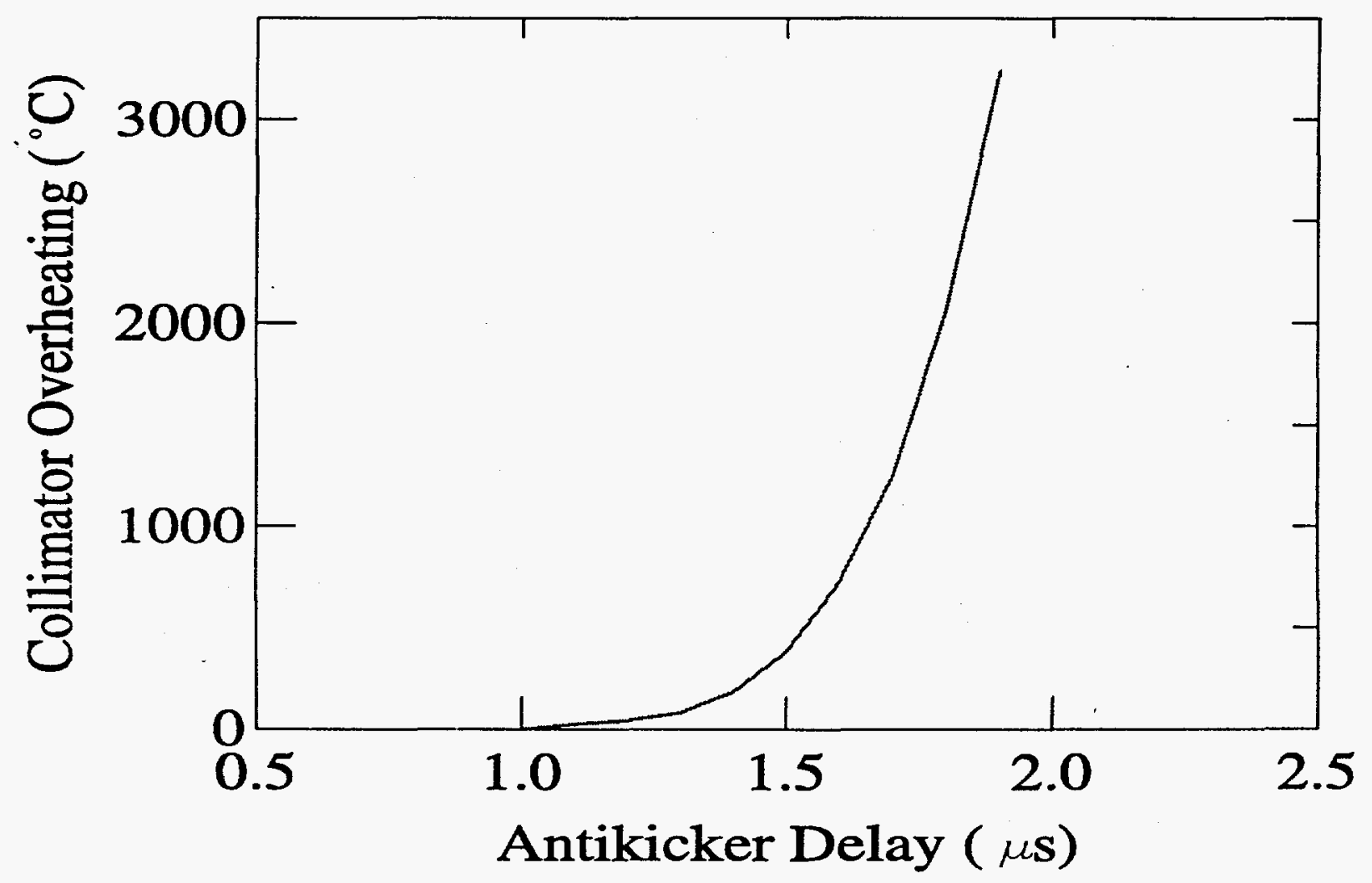

Fig. 9. Peak temperature rise in collimator jaws vs antikicker delay. 


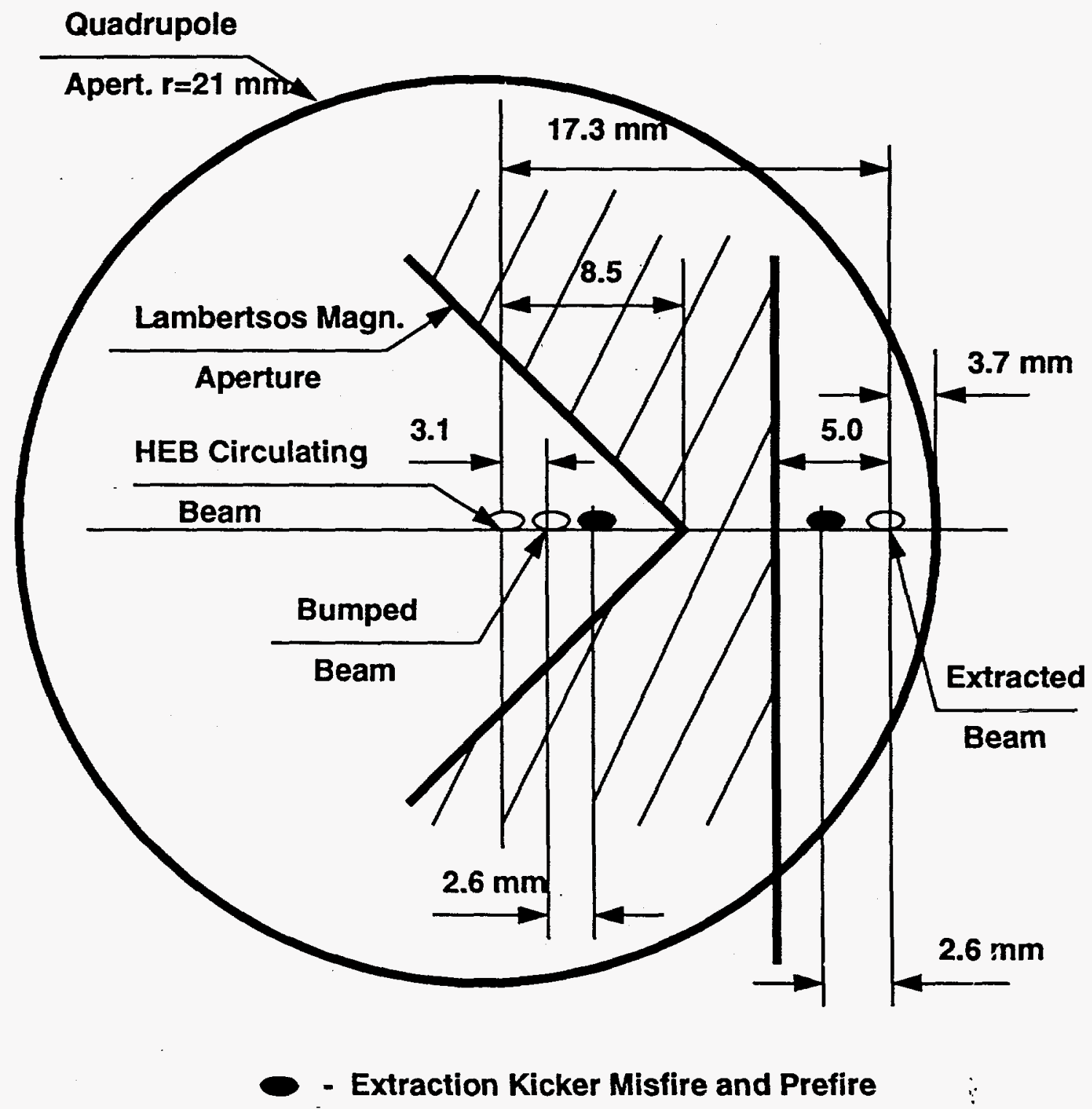

Fig.10. Beam positions at the upstream end of the HEB extraction Lambertson magnet. 


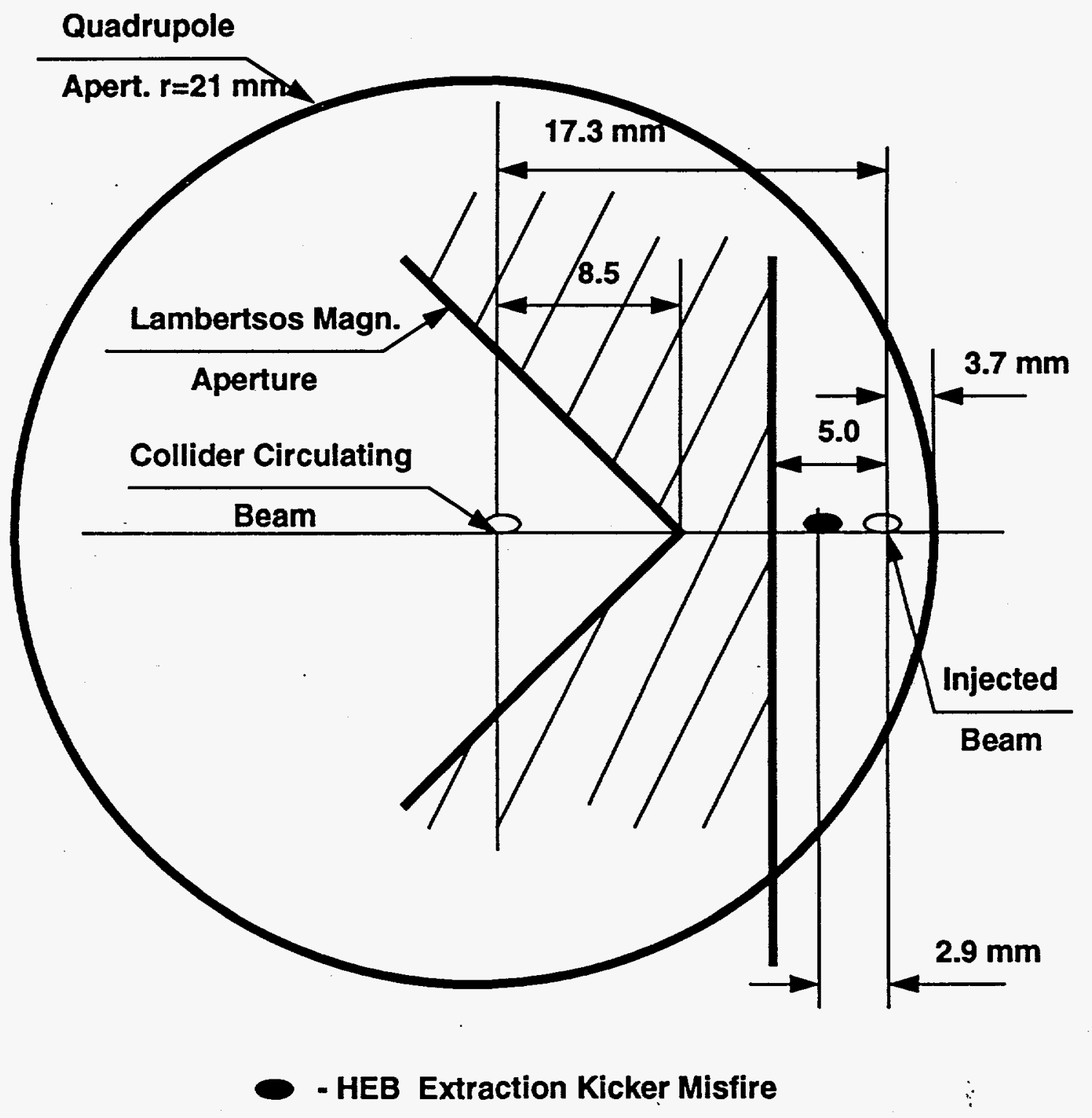

Fig.11.Beam positions at the downstream end of the collider injection Lambertson magnet. 


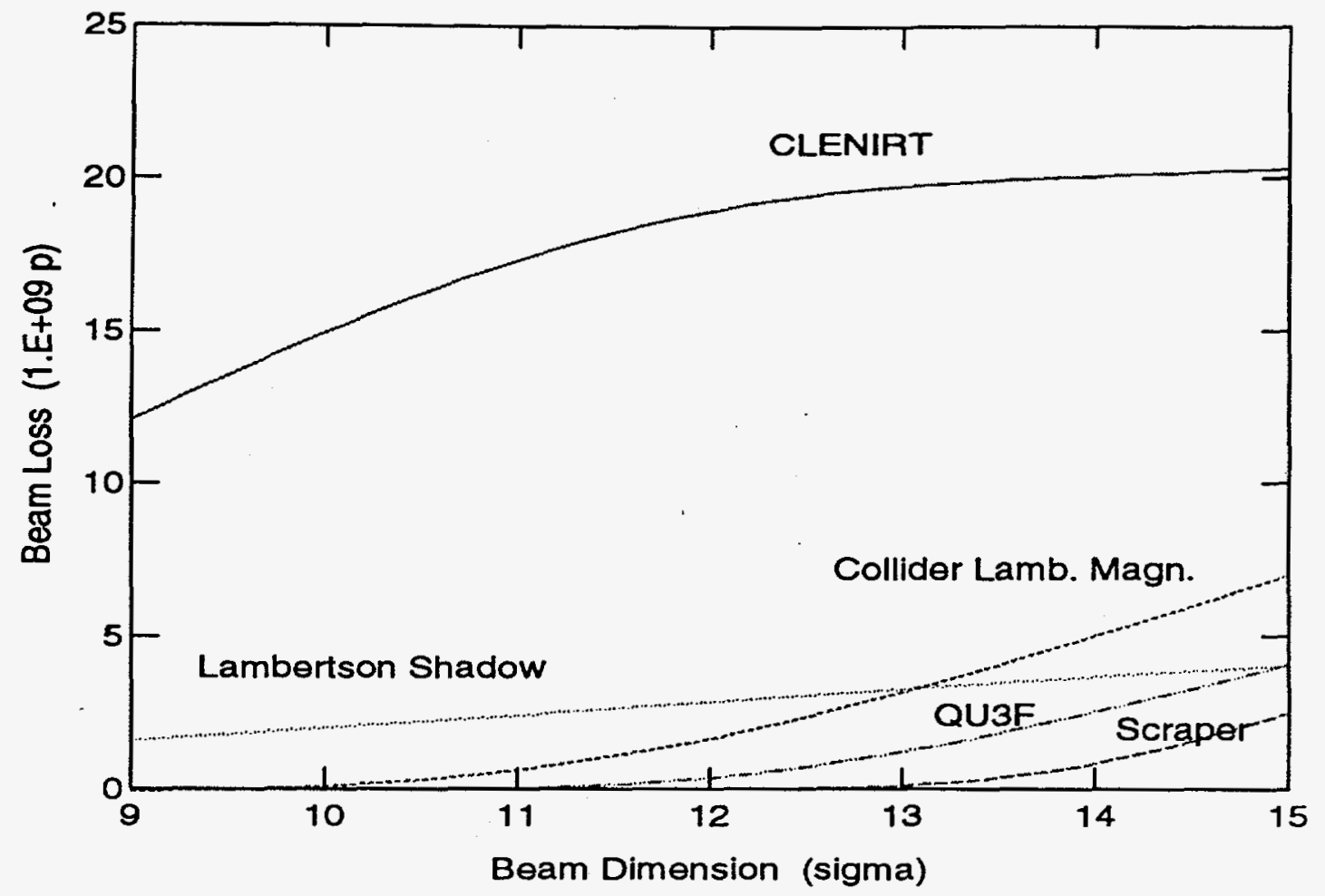

Fig.12. Beam loss at HEB extraction kicker misfire as a function of beam size.

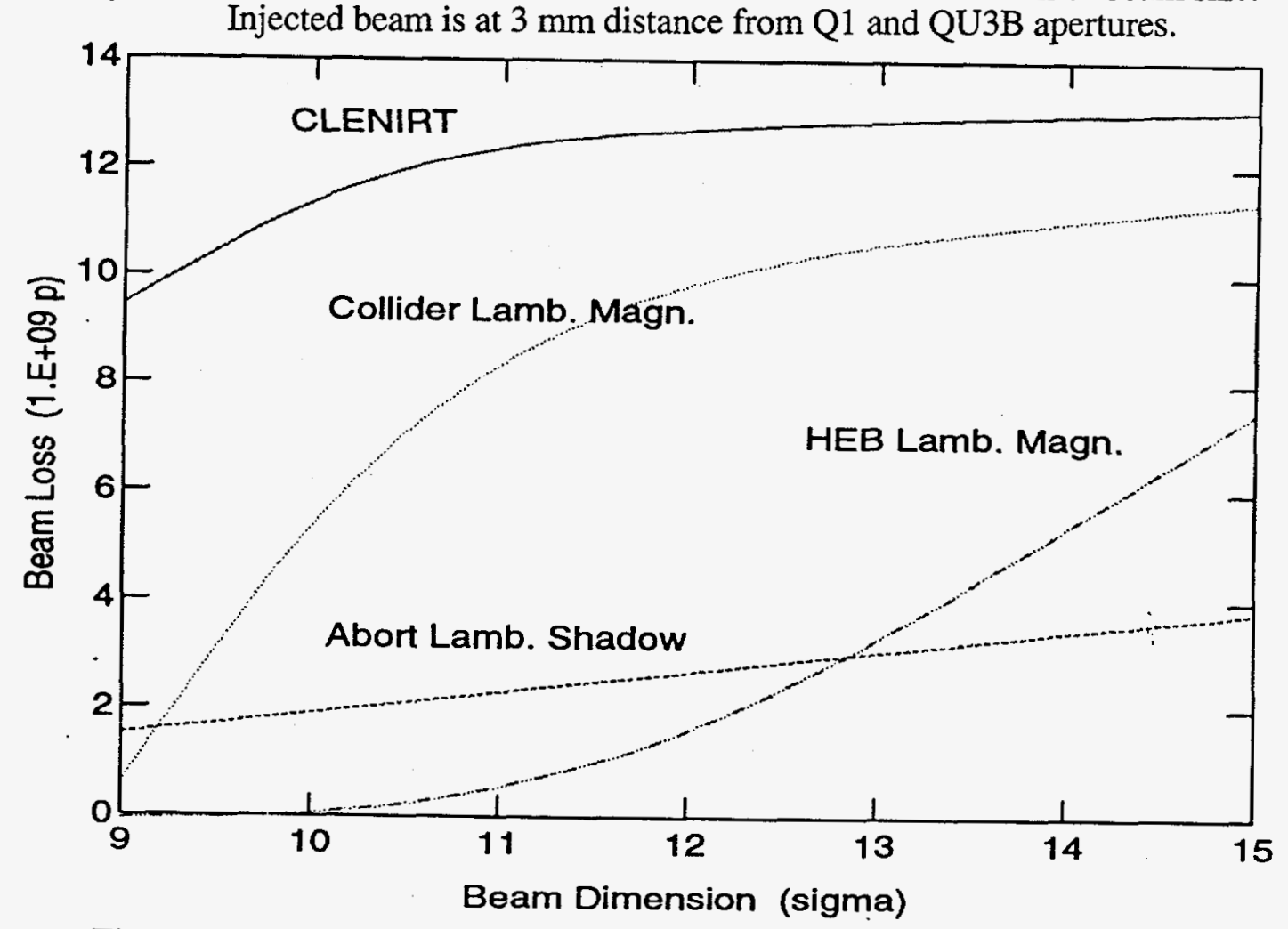

Fig.13. Beam loss at HEB extraction kicker misfire as a function of beam size. Injected beam is at $3.7 \mathrm{~mm}$ distance from Q1 and QU3B apertures. 


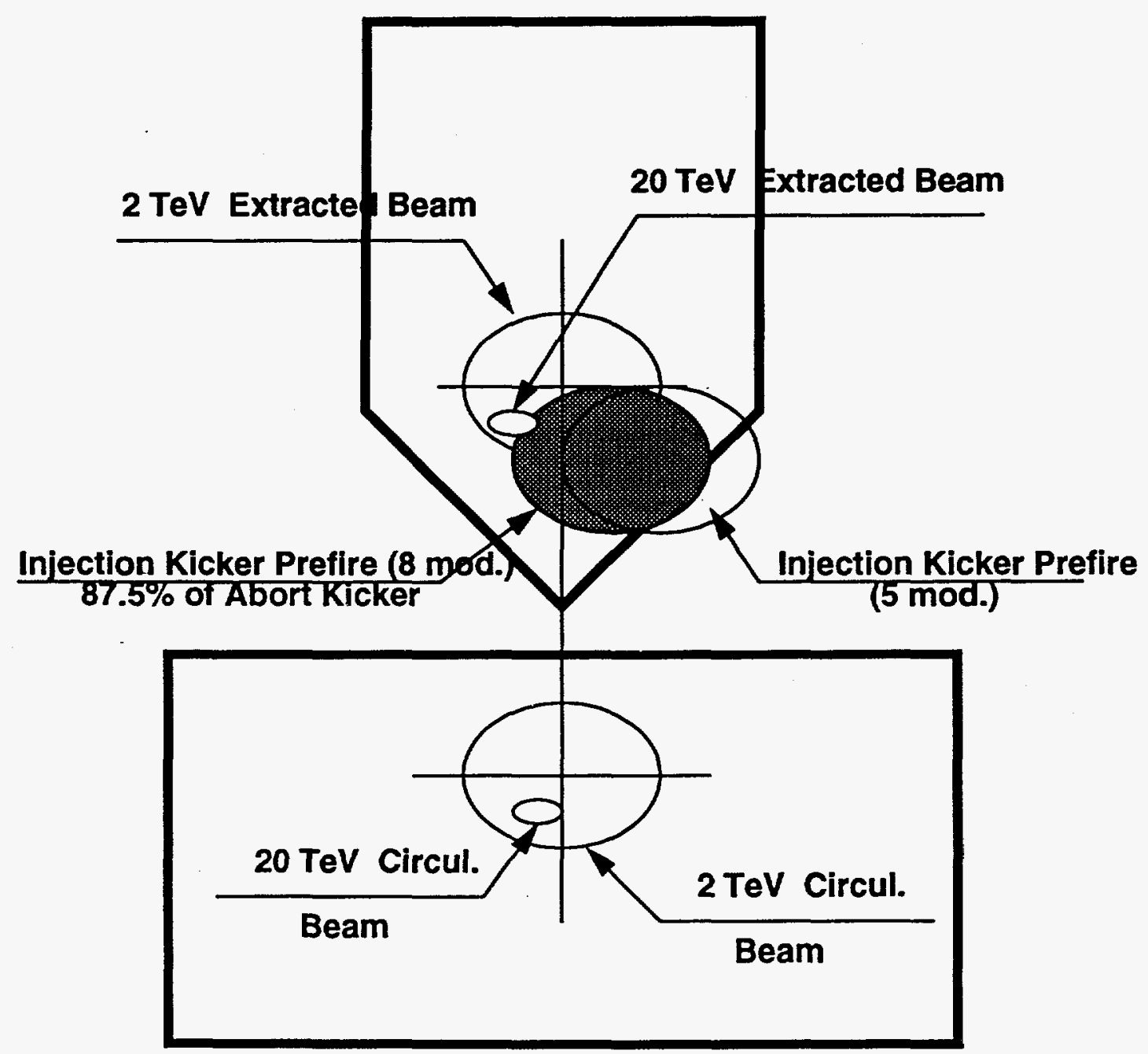

Fig.14. Circulating and aborted beam positions upstream the collider abort Lambertson shadow at injection kicker prefire. 


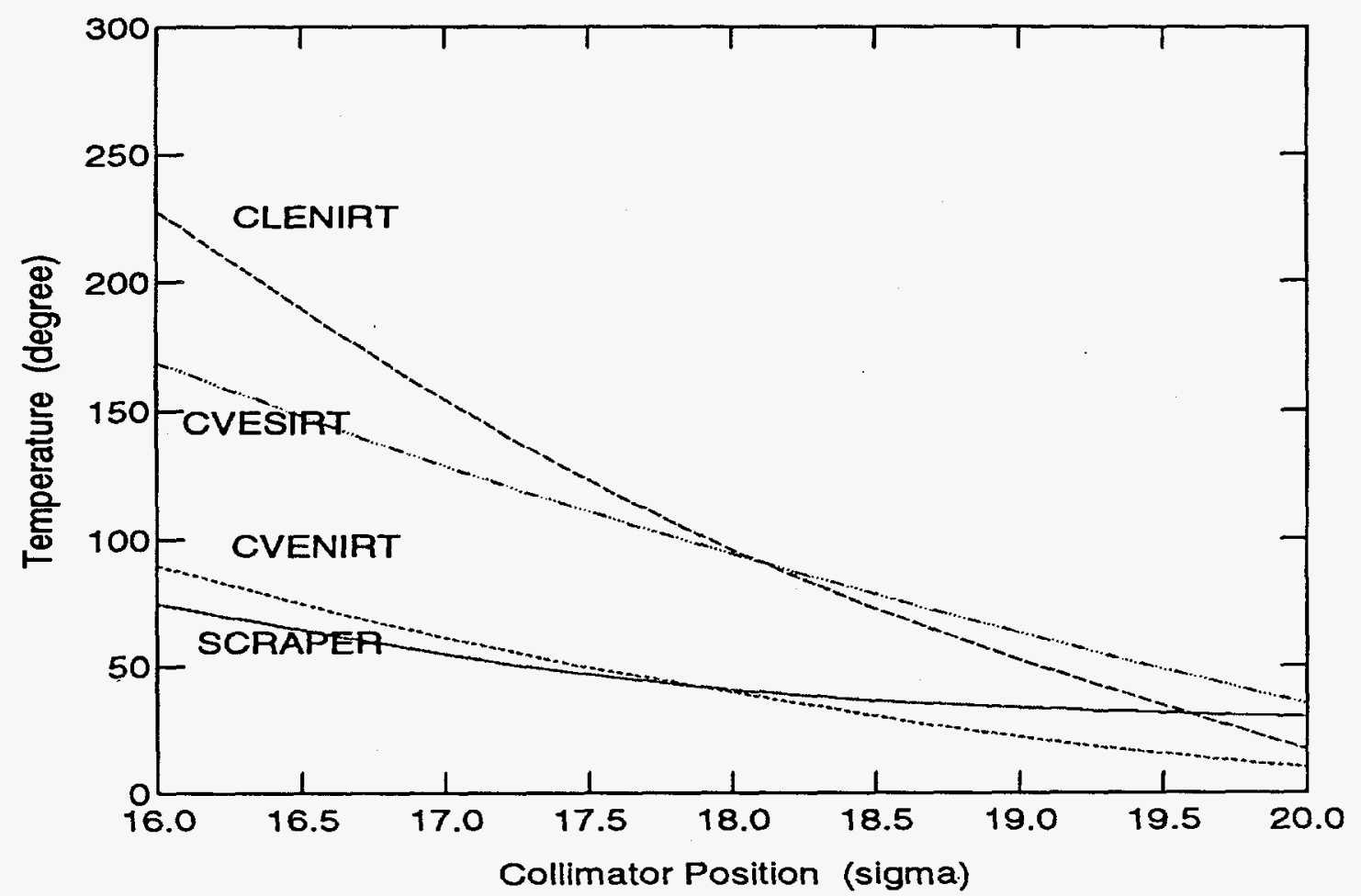

Fig.15. Peak instantaneous temperature rise in collimator at collider injectionkicker prefire and misfire vs jaw position. Kicker consists of 5 modules.

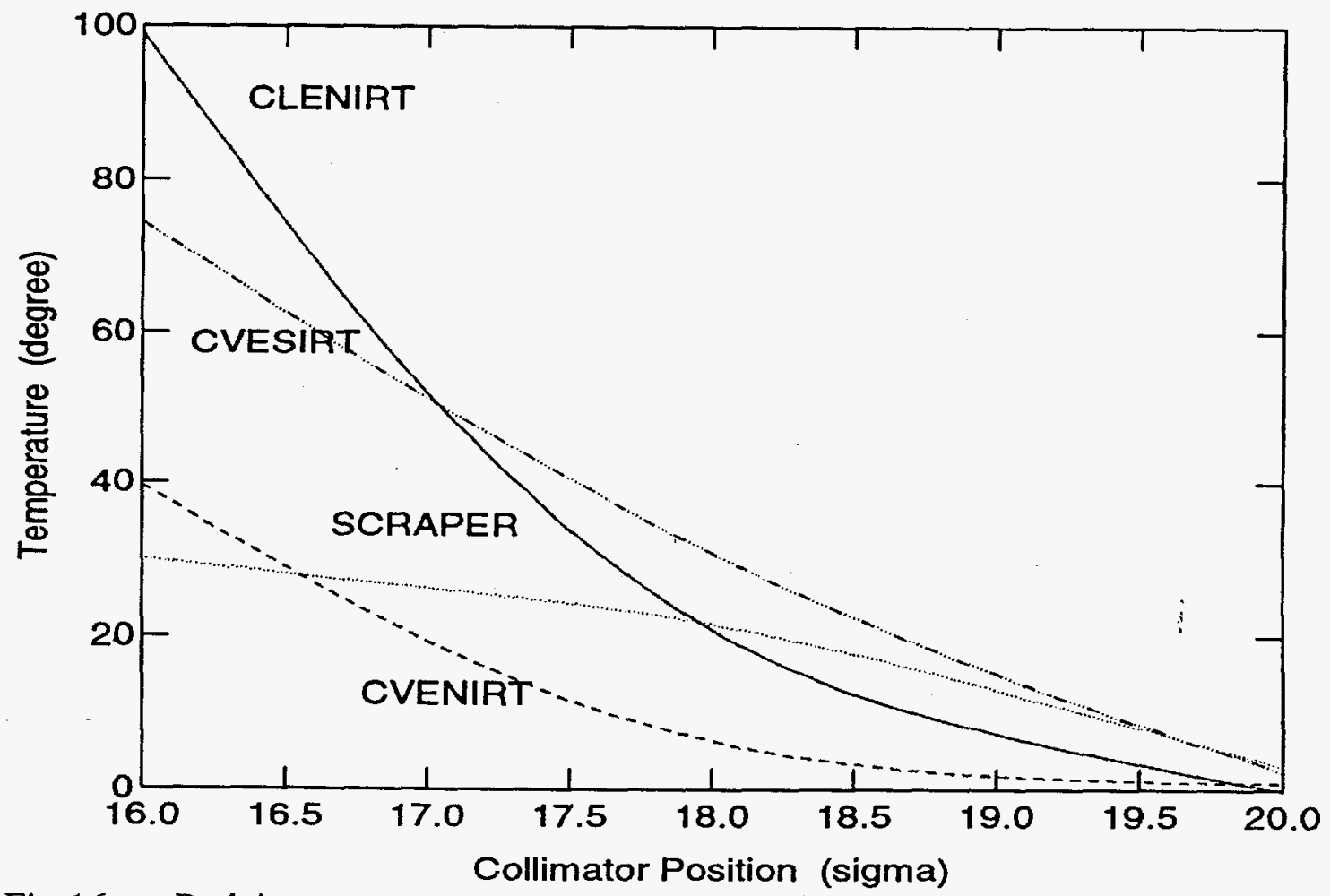

Fig.16. Peak instantaneous temperature rise in collimator at collider injection kicker prefire and misfire vs jaw position. Kicker consists of 6 modules. 


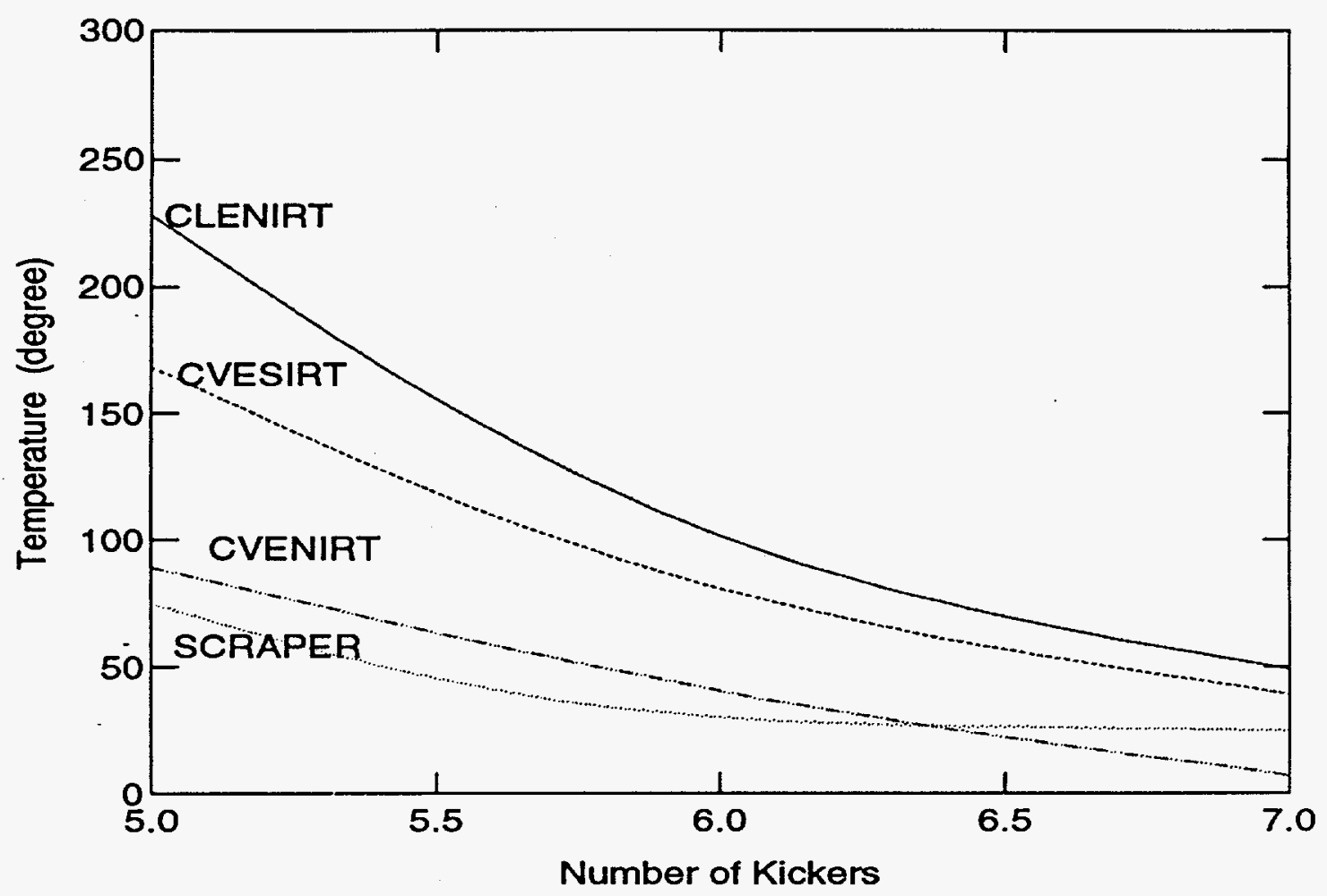

Fig.17. Peak instantaneous temperature rise in collimator at collider injection kicker prefire and misfire as a function of number of kicker modules.

Collider Injection

Kicker Rise Time (1.5 $\mu \mathrm{s})$

Collider Abort Gap

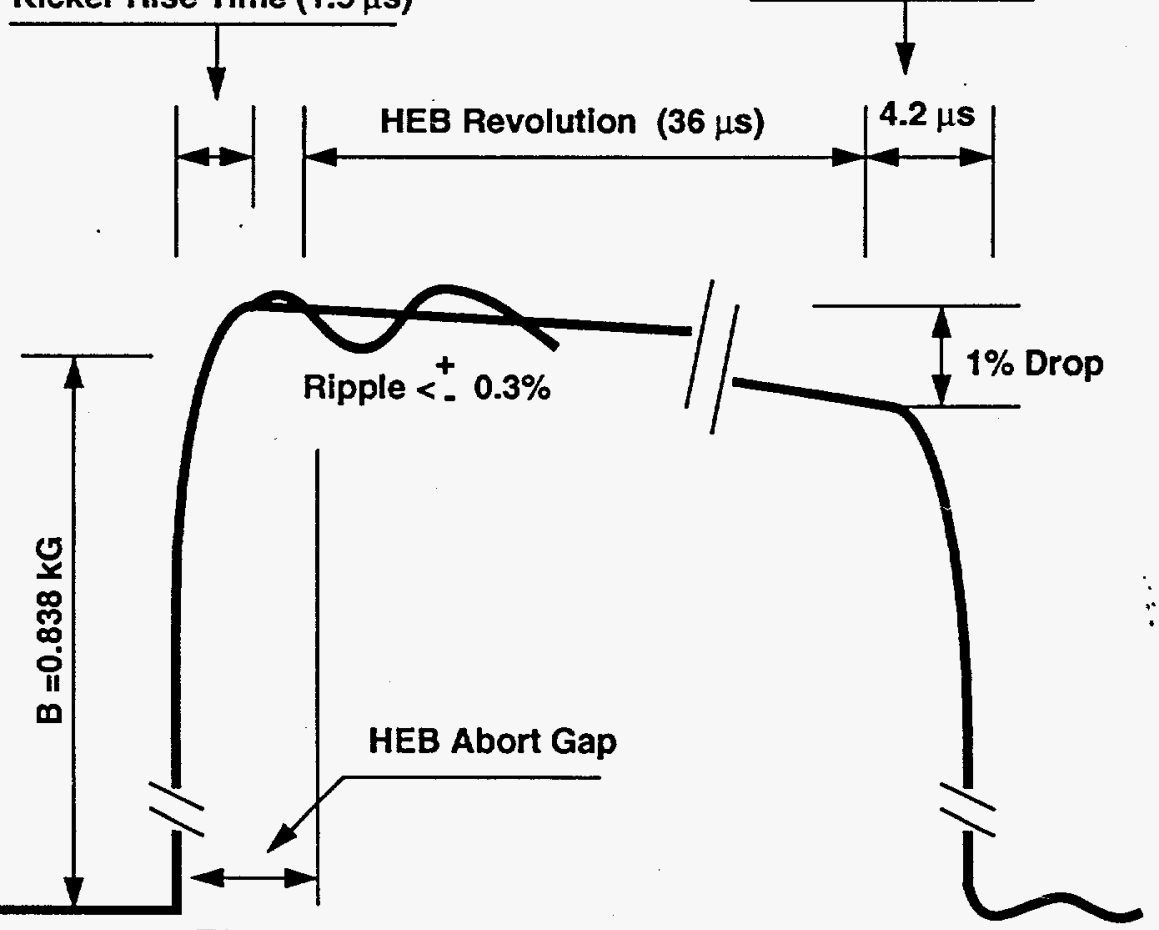

Fig.18. HEB extraction kicker pulse form. 


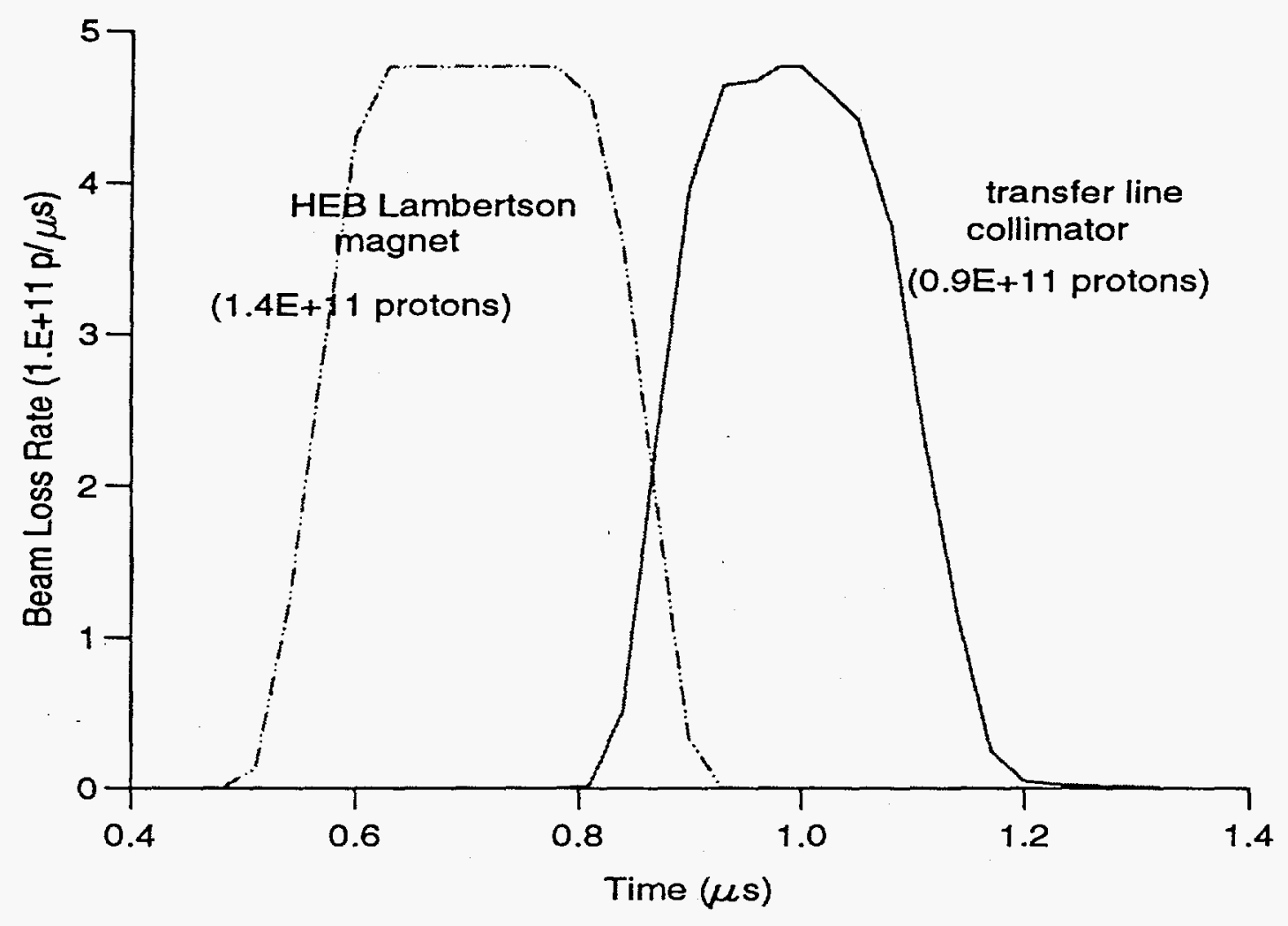

Fig.19. Beam loss at HEB extraction kicker timing errors. 

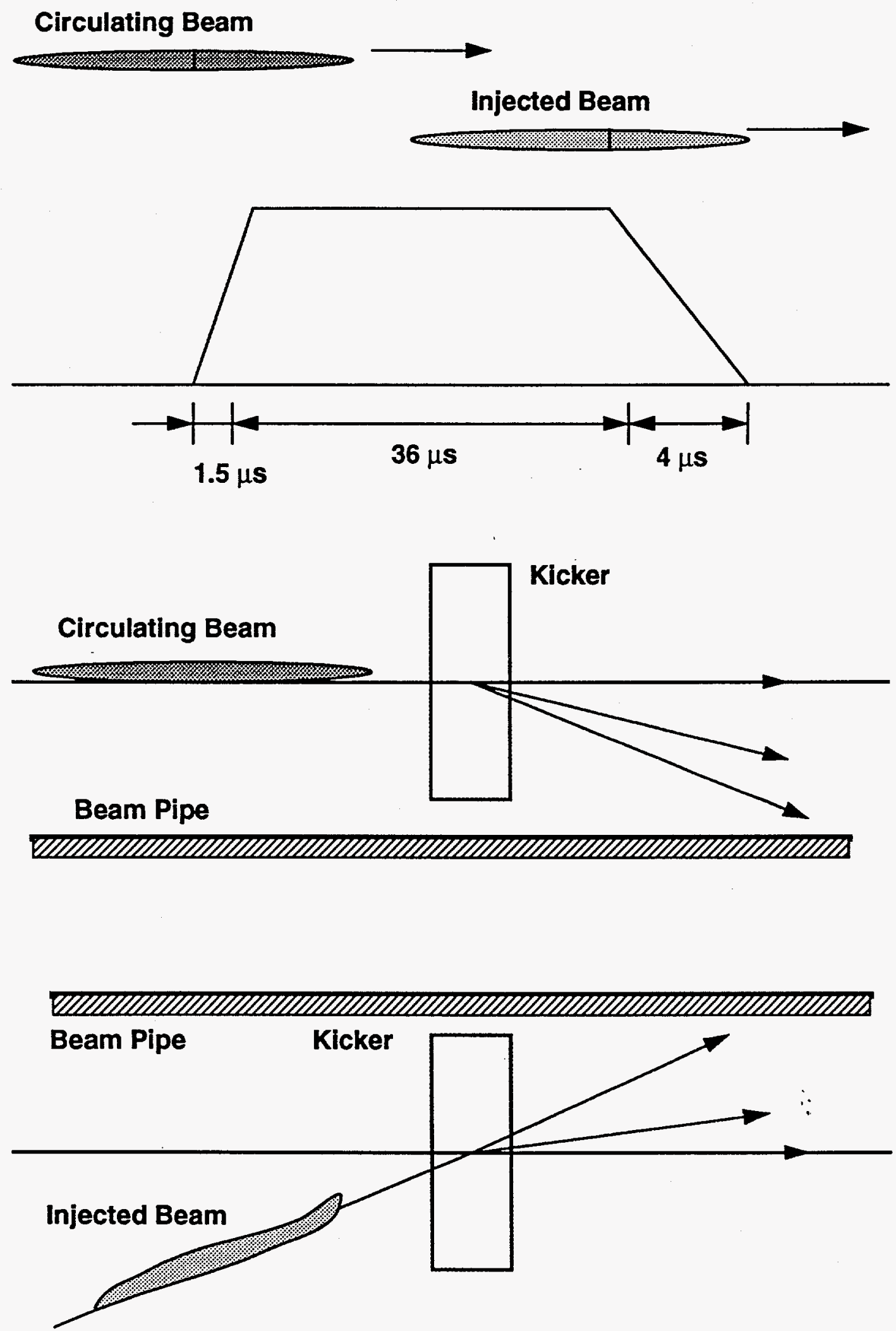

Fig.20. Scheme of beam loss at collider injection kicker timing error. 


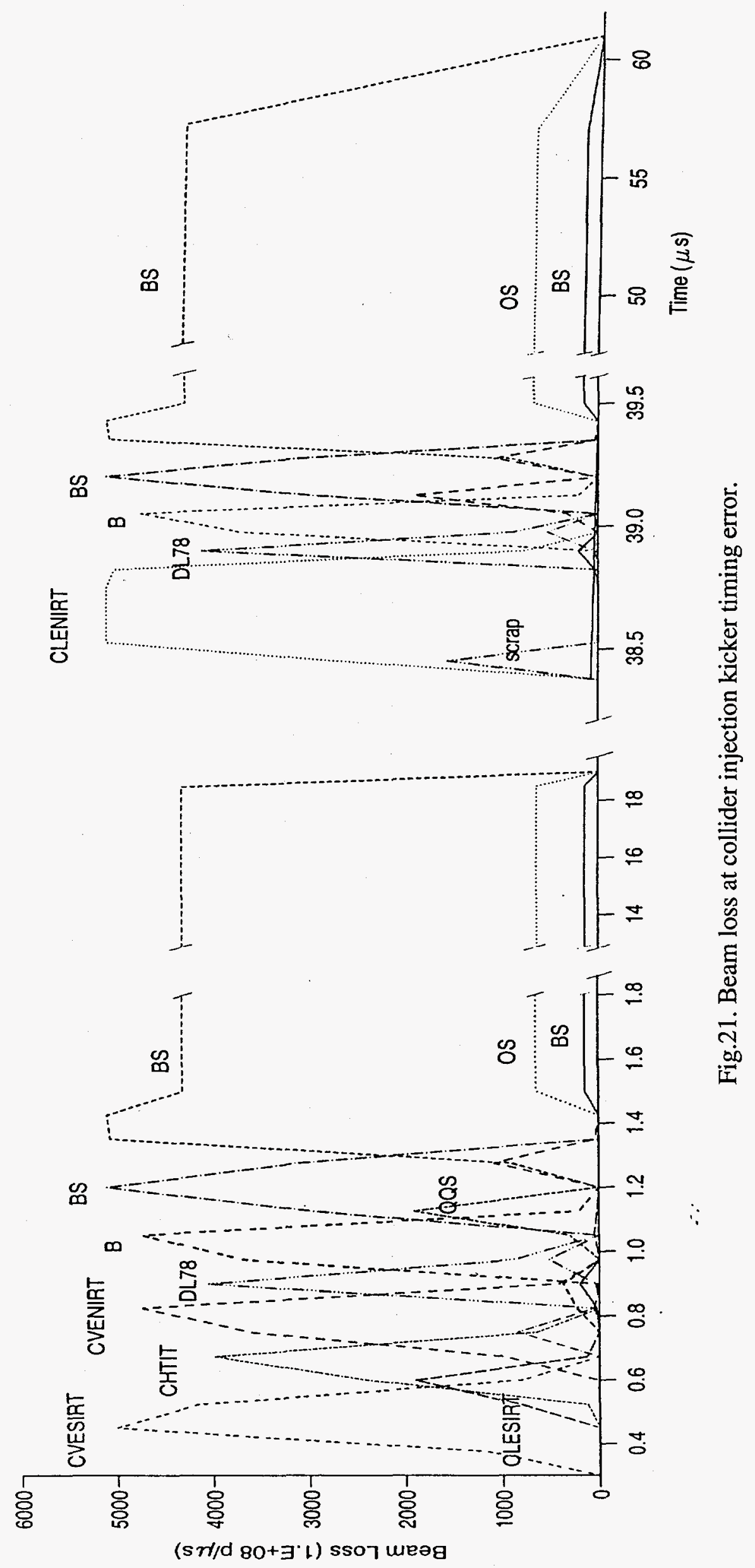



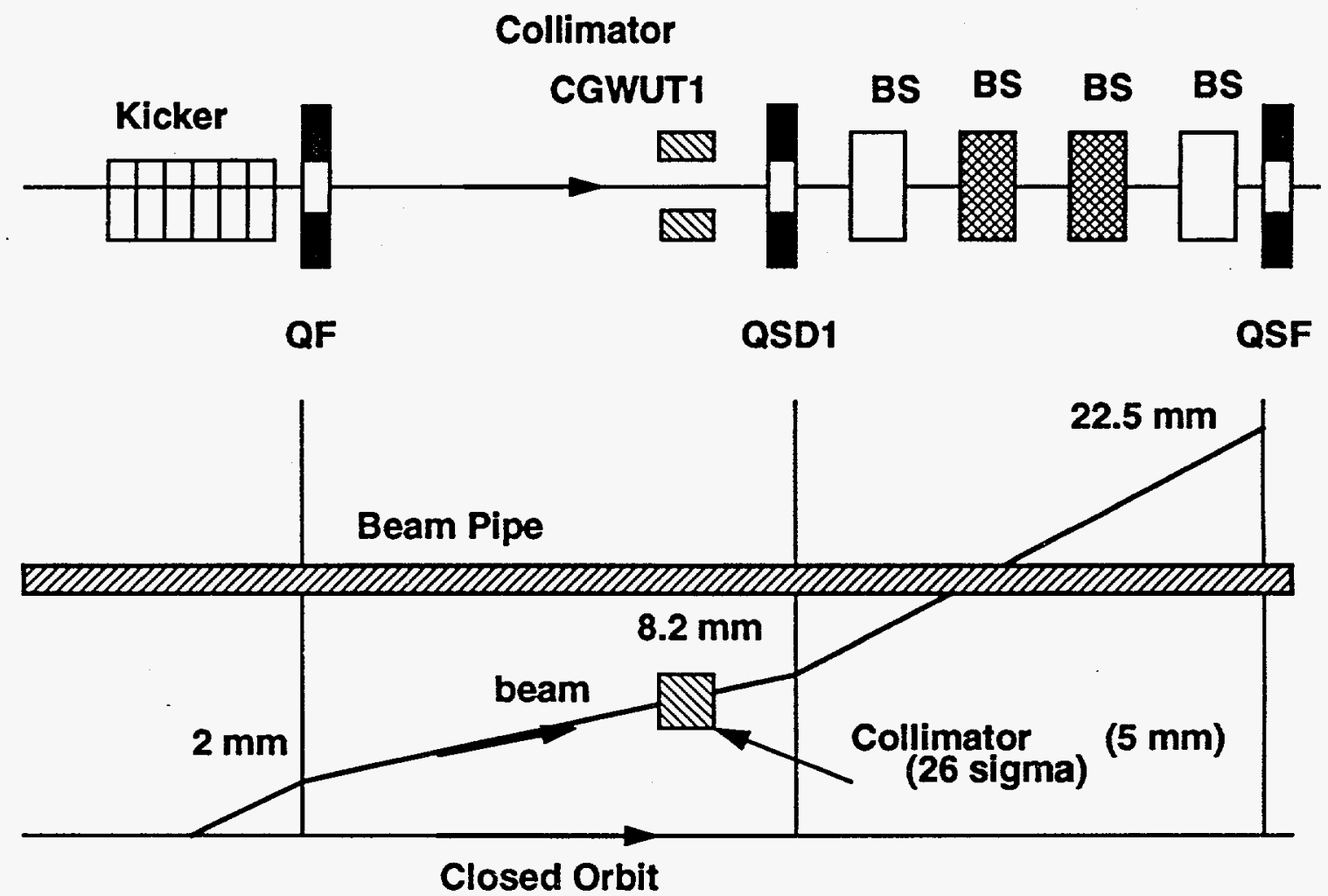

Fig.22. Fixed aperture collimator location downstream collider injection kicker. 